\title{
URSI National Committee Report, XIV General Assembly, Tokyo, September 1963: Commission 1. Radio Measurement Methods and Standards
}

\author{
Review of developments occurring within the United States in the fields of Radio \\ Measurement Methods and Standards during the triennium 1960 through 1962. \\ 1. Atomic frequency and time interval standards. R. C. Mockler \\ 2. RF and microwave power measurements. G. F. Engen and N. T. Larsen. \\ 3. Standards and measurements of attenuation. Impedance and phase shift. R. W. \\ Beatty. \\ 4. Pulsed and CW sinusoidal voltage and current measurements. M. C. Selby \\ 5. Radio noise measurement methods and standards. W. W. Mumford \\ 6. Measurements at millimeter and submillimeter wavelengths. R. G. Fellers \\ 7. Precise measurements of distance and of the velocity of light using lasers. P. L. Bender \\ Appendix: Measurements standards and calibration laboratories in the United States. \\ C. E. White
}

\section{Atomic Frequency and Time Interval Standards}

\author{
Richard C. Mockler
}

Radio Standards Laboratory, National Bureau of Standards, Boulder, Colo.

Probably the most noteworthy accomplishment in the period 1960-61-62 has been the development of the hydrogen maser. The HCN maser may also have application as a frequency standard, but no serious attempt to evaluate its usefulness to this purpose has been made. A thallium beam is finally under critical test as a frequency standard. Considerable technological development of cesium beams, ammonia masers, and optically pumped gas cells has taken place. Commercial rubidium gas cells of excellent quality are now available, together with much improved new models of commercial cesium beam standards. Techniques have been developed for synchronizing and comparing widely separated clocks by propagated signals. It is now possible to compare atomic frequency standards using VLF transmissions to about 2 parts in $10^{11}$ over large distances.

\subsection{Atomic Beam Standards}

The hydrogen atomic beam maser has been shown to have an interaction time the order of 1 sec, from which is inferred a spectral line width of about $1 \mathrm{c} / \mathrm{s}$. This is the narrowest line employed in any of the present-day frequency standards. The extreme narrowness of the line reduces very substantially the effects of "frequency pulling" by the resonant cavity on the emission frequency. As a consequence of the large number of collisions taking place within the decay time, there is practically no first-order Doppler shift. Two hydrogen masers at Harvard have demonstrated a relative stability of 1 part in $10^{12}$ over a 12-hr period. A frequency shift of about 1 part in $10^{11}$ exists as a result of interaction with the wall coatings. There is hope of eliminating this shift to a large extent [Goldenberg, Kleppner, and Ramsey, 1960; Goldenberg, Kleppner, and Ramsey, 1961; Kleppner, Goldenberg, and Ramsey, 1962 a and b; Ramsey and Kleppner, 1962; Vessot and Peters, 1962]. Although hydrogen is much more sensitive to a magnetic field than is thallium or even cesium, its narrow line width will allow the field to be reduced to a very low level. However, it remains to be determined just how low this field may be reduced. Intensity may suffer drastically at the desirable field level as a result of "Majorana flop."

NBS has made preliminary measurements on a thallium beam, obtaining precisions of 5 parts in $10^{13}$ in a given day. However, the day-to-day frequency measurements show a standard deviation of the mean of 4 parts in $10^{12}$. This scatter in the day-to-day measurements has been found to be attributable to the rather poor construction of the microwave structure exciting the transition. From the present data it is inferred that significantly higher accuracy can be obtained with thallium as opposed to cesium if a suitable microwave structure is used. 
The United States Frequency Standard (USFS) and its alternate have undergone rather extensive tests through the past 4 years at NBS. Their accuracy is about 1 part in $10^{11}$ and precision of about 2 parts in $10^{13}$ for $12-\mathrm{hr}$ averaging times. $\chi^{2}$ tests demonstrate a gaussian distribution of the data. Manual and servo measurements of frequency agree to the precision of measurement $\left( \pm 2 \times 10^{-12}\right)$ over a period of 1 year [Mockler, Beehler, and Snider, 1960; Mockler, 1961; Beehler, Atkinson, Heim, and Snider, 1962].

\subsection{Optically Pumped Standards}

Extensive development and analysis of frequency standards employing optical pumping techniques have yielded a rubidium gas cell standard with a drift rate of about 1 part in $10^{11}$ per month, and a temperature coefficient of 1 part in $10^{11}$ per ${ }^{\circ} \mathrm{C}$. [Carpenter, Beaty, Bender, Saito, and Stone, 1960].

Investigation of alkali metal gas cells employing buffer gases show a shift in frequency when the intensity of the exciting resonance light is varied. High buffer gas pressures reduce this shift considerably [Arditi and Carver, 1961; Arditi, 1961]. Arditi and Carver have measured the hyperfine structure (hfs) separation as a function of the buffer gas pressure, temperature, and intensity of the pump light source. The rubidium hyperfine structure separation has been measured to $\pm 3 \mathrm{c} / \mathrm{s} \quad\left(\nu_{0}=\right.$ $6,834,682,614)$ by Penselin et al. [Penselin, Moran, and Cohen, 1961].

Tests on a commercial rubidium gas cell standard give the following results (where $\sigma$ denotes the standard deviation of frequency):

$\sigma=2.5$ parts in $10^{12}$ for a 10 -hr run with 24 -min averaging times;

$\sigma=2$ parts in $10^{11}$ for a 10 -min run and $1 / 4$-sec a veraging times;

$\sigma=4.5$ parts in $10^{11}$ for a run of 160 days [Packard, $1962]$.

\subsection{Molecular Beam Masers}

Marcuse has successfully operated an HCN maser at $88.6 \mathrm{Gc} / \mathrm{s}$ [Marcuse, 1961; Marcuse, 1962]. An effort is being made to observe the $(J=2, K=1) \rightarrow$ $(J=1, K=1)$ transition in $\mathrm{ND}_{3}$ at $618 \mathrm{Gc} / \mathrm{s}$ [Derr, Gallagher, and Lichtenstein, 1961].

The ammonia maser has been employed as a stable signal source in order to spectrum-analyze frequency-multiplied signals from. crystal oscillators and stabilized klystrons. The purpose of the experiments was to determine the short time stability of these signal sources and to appraise their usefulness in the excitation of cesium beam standards. This ammonia maser spectrum analyzer has a band width of about $3 \mathrm{c} / \mathrm{s}$ at $24,000 \mathrm{Mc} / \mathrm{s}$ [Barnes and Heim, 1961; Barnes and Mockler, 1960].

Barnes et al., have developed an $\mathrm{N}^{14} \mathrm{H}_{3}$ maser resettable to $3 \times 10^{-11}$ [Barnes, Allan, and Wain- wright, 1962]. A substantial improvement is expected if $\mathrm{N}^{15} \mathrm{H}_{3}$ is used. In their device a correction signal is obtained by Zeeman modulating which is used to continuously servo the cavity to the $\mathrm{NH}_{3}$ resonance frequency. The maser signal stabilizes a frequency multiplier chain and imparts to it a stability of about $\pm 4 \times 10^{-12}$ for periods the order of $1 \mathrm{hr}$.

\subsection{Atomic Time}

The Naval Observatory and the National Physical Laboratory determinded the frequency of the hyperfine structure separation in cesium in terms of Ephemeris Time. This frequency is $9,192,631,770 \pm 20 \mathrm{c} / \mathrm{s}$ [Markovitz, 1962].

NBS has established a separate atomic time scale based solely on the United States Frequency Standard, assuming the hfs separation in cesium to be $9,192,631,770.00$. . . c/s for purposes of research regarding the redefinition of the second in terms of an atomic transition. NBS atomic time has been assigned to WWV time pulses beginning in October 1957. These assignments have been compared to similar assignments of time by the Naval Observatory according to their A.1 scale. Analysis of the data between October 1957 and August 1962 shows that the NBS and A.1 scales are diverging at an average rate of $2 \times 10^{-11} \mathrm{sec} / \mathrm{sec}$ [Newman, Fey, and Atkinson, 1963]. Although the rates of the two clock systems agree very well, the actual time when the two systems were chosen to be in coincidence (Jan. 1, 1958) has an uncertainty of about \pm 1 msec. It is intended that the Loran-C system will be used to synchronize the NBS clocks with A.1 time to 1 $\mu$ sec. The total delay time has not yet been determined.

\subsection{Frequency and Time Interval Com- parisons}

The two cesium beam United States Frequency Standards (USFS) were compared throughout the period 1960-61-62. Their frequency difference is 1.6 part in $10^{11}$. This difference remained constant within this time period to \pm 2 parts in $10^{12}$ even though the machines were partially disassembled and moved to another laboratory, $C$ field structures and shielding were changed, and frequency multipliers, deflecting magnets, and rf structures were changed.

Almost daily comparison of the United States Frequency Standards with the commercial beam and gas cell secondary standards at NBS demonstrate the newer models of these devices to be commonly stable within \pm 2 parts in $10^{12}$ from day to day. A vast amount of this data has not yet been critically analyzed.

Atomic frequency standards in different parts of the world can now be best compared by monitoring the following VLF frequency stabilized transmissions: NBA (Canal Zone, $18 \mathrm{kc} / \mathrm{s}$ ), GBR (England, $16 \mathrm{kc} / \mathrm{s}$ ), WWVB (near Boulder, Colo., $60 \mathrm{kc} / \mathrm{s}$ ), and 
WWVL (near Boulder, Colo., $20 \mathrm{kc} / \mathrm{s}$ ). NBS assigns corrections to these transmissions with respect to the United States Frequency Standard; the Naval Observatory assigns corrections to NBA and GBR according to the A.1 system; and the European nations assign corrections according to their own atomic standards based on the frequency $9,192,631,770 \mathrm{c} / \mathrm{s}$ for cesium. WWVB and WWVL are of low power and do not have the coverage of NBA and GBR.

Analysis of the data covering the period September 1960 to February 1961 for eight atomic frequency standards located at NBS, NRL, Naval Observatory, Cruft, NRC, NPL, CNET, and Neuchâtel shows a maximum divergence of 8 parts in $10^{10}$ and a minimum divergence of 3 parts in $10^{10}$. More typically, the mean difference between standards was 1 to 2 parts in $10^{10}$ with fluctuations from month to month of the same order [Richardson, Beehler, Mockler, and Fev, 1961].

Data from November 30, 1959, to June 30, 1960, gave a difference between the United States Frequency Standards and the NPL standard as -6 parts in $10^{11}$ for one propagation link and +1.2 parts in $10^{10}$ for another propagation link. Comparison via a single propagated signal could not be made at the time. More recent and more direct comparisons show much better agreement. Data over the past $1 \frac{1}{2}$ yrs have not yet been completely analyzed.

Simultaneous phase measurements made at Cambridge, Mass., and Banbury, England, on the propagated signals from GBR were made in order to resolve the observed fluctuations into a contribution caused on the propagation path and a contribution produced by fluctuations in the oscillators. The fluctuations in transmission time were about $2 \mu \mathrm{sec}$. The corresponding contribution to the error of transatlantic frequency measurement is 2 parts in $10^{11}$ for a measurement time of $24 \mathrm{hr}$ [Pierce, 1960].

Reder et al., studied the problem of synchronizing clocks separated by large distances by physically transporting atomic clocks and maintaining synchronization via VLF transmissions. Their conclusions were that clocks anywhere on the surface of the earth could be synchronized to $5 \mu$ sec or better [Reder and Winkler, 1960; Winkler and Reder, 1960; Reder, Brown, Winkler, and Bichart, 1961].

The Loran-C navigational system operating on a basic frequency of $100 \mathrm{kc} / \mathrm{s}$ has been demonstrated to be capable of synchronizing clocks separated by large distances to $1 \mu \mathrm{sec}$ [Doherty, Hefley, and Linfield, 1960]. Delay times have evidently not been determined except by the measured two-way propagation time. It is inferred that frequency may be compared by such a system. with a precision of 1 part in $10^{12}$ in 1 day and to 1 part in $10^{13}$ in about 10 days [Markowitz, 1962]. NBS and the Naval Observatory are cooperating in the development of the Loran-C system to provide time synchronization with the highest possible precision.

Joint experiments for time synchronization were performed by the Naval Observatory and the National Physical Laboratory, using the Telstar satel- lite, in August 1962. It was concluded that clocks at these two locations could be synchronized to about $1 \mu$ sec. It is believed that this could be im.proved to $0.1 \mu \mathrm{sec}$, in which case a frequency comparison to 1 part in $10^{13}$ could be accomplished in 10 days. Distances to the satellite determined by celestial mechanics and distances given by the travel time of the signal multiplied by the volocity of light agree to about $1 \mathrm{~km}$, indicating that the delay time can be calculated to about $3 \mu$ sec. This might very well be improved with better range data.

Time signals from a clock in the navigational satellite Transit are being monitored by the Naval Observatory. The accuracy of measurements is now about $100 \mu \mathrm{sec}$.

\section{References}

Anderson, T. C., and F. G. Merrill (1960). Crystal-controlled primary frequency standards: Latest advances for longterm stability, IRE Trans. Instr. I-9, 136-140.

Arditi, M. (1961). Frequency control by gas cell standards, Proc. 15th Annual Symp. Frequency Control (U.S. Army Research and Development Lab., Ft. Monmouth, N.J.), pp. $181-202$.

Arditi, M., and T. Carver (1961). Pressure, light and temperature shifts in optical detection $0-0$ hyperfine resonance of Alkali metals, Phys. Rev. 124, 800.

Baltzer, O. J. (1961). Frequency control by means of a phase tracking VLF receiver, Proc. 15th Annual Symp. Frequency Control (U.S. Army Research and Development Lab., Ft. Monmouth, N.J.), pp. 251-260.

Barnes, J. A., D. W. Allan, and A. E. Wainwright (1962). The ammonia beam maser as a standard of frequency, IRE Trans. Instr. I-II, 26-30.

Barnes, F., D. Burkhard, and M. Mizushima (1961). Choice of a molecular transition for frequency control in the millimeter wave region, Proc. 15th Annual Symp. Frequency Control (U.S. Army Research and Development Lab., Ft. Monmouth, N.J.), pp. 204-209.

Barnes, F. S. (1962). The choice of a molecule for a beam frequency standard, IRE Trans Instr. I-11, 191-195.

Barnes, J. A., and L. E. Heim (1961). A high-resolution ammonia beam-maser-spectrum analyzer, IRE Trans. Instr. I- 10, 4-8.

Barnes, J. A., and R. C. Mockler (1960). The power spectrum and its importance in precise frequency measurements, IRE Trans. Instr. I-9, 149-154.

Beehler, R. E., W. R. Atkinson, L. E. Heim, and C. S. Snider (1962). A comparison of direct and servo methods for utilizing cesium beam resonators as frequency standards, IRE Trans. Instr. I-11, 231-238.

Beehler, R. E., R. C. Mockler, and C. S. Snider (1960). A comparison of atomic beam frequency standards, Nature 187, $681-682$.

Beers, Y. (1961). Comparison of the sensitivities of the beam maser and cavity absorption spectrometers, Rev. Sci. Instr. 32, 23-27.

Brans, C., and R. H. Dicke (1961). Mach's principle and a relativistic theory of gravitation, Phys. Rev. 124, 925.

Carpenter, R. J., E. C. Beaty, P. L. Bender, S. Saito, and R. O. Stone (1960). A prototype rubidium vapor frequency standard, IRE Trans. Instr. I-9, 132-135.

Cutler, L. S. (1961). A frequency standard of exceptional spectral purity and long term stability, IRE International Convention Record 9, 183-190.

Derr, V. E., J. J. Gallagher, and M. Lichtenstein (1961). Deuterated ammonia submillimeter maser - a progress report, Proc. 15th Annual Symp. Frequency Control (U.S. Army Research and Development Lab., Ft. Monmouth, N.J.), pp. $210-224$.

Dicke, R. H. (1962). Mach's principle and invariance under transformation of units, Phys. Rev. 125, 2163. 
Dicke, R. H. (1962). Timekeeping satellites, Proc. 16th Annual Symp. Frequency Control (U.S. Army Research and Development Lab., Ft. Monmouth, N.J.), p. 249.

Doherty, R., G. Hefley, and R. Linfield (1960). Timing potential of Loran-C, Proc. 14th Annual Symp. Frequency Control (U.S. Army Research and Development Lab., Ft. Monmouth, N.J.), pp. 276-297.

Ganssen, A. (1962). The proton magnetic resonance oscillator, a radio frequency source of high spectral purity, IRE Trans. Instr. I-11, 166-170.

George, James (1962). Recent advances in cesium beam technologv and characteristics of Rabi and Ramsey cesium beam tubes 17 inches in length, IRE Trans. Instr. I-11, $250-256$.

Giordmaine, J. A., and T. C. Wang (1960). Molecular beam formation by long parallel tubes, J. Appl. Phys. 31, 463-471.

Goldenberg, H. M., D. Kleppner, and N. F. Ramsey (1960). Atomic hydrogen maser, Phys. Rev. Letters 5, 361-362 .

Goldenberg, H., D. Kleppner, and N. F. Ramsey (1961). Atomic beam resonance experiments with stored beams, Phys. Rev. 123, 530.

Hafner, E. (1960). Stability of crystal oscillators, Proc. 14th Annual Symp. Frequency Control (U.S. Army Research and Development Lab., Ft. Monmouth, N.J.), pp. 192-199.

Hastings, H., and W. Markowitz (1960). Stabilization of VLF transmissions at NBS, Proc. 14th Annual Symp. Frequency Control (U.S. Army Research and Development Lab., Ft. Monmouth, N. J.), p. 275.

Helmer, J. C., F. B. Jacobus, and P. A. Sturrock (1960). Focusing molecular beams of $\mathrm{NH}_{3}$, J. Appl. Phys. 31, $458-463$

Hopfer, S. (1960). Design considerations for a self-contained ammonia maser oscillator, Proc. 14th Annual Symp. Frequency Control (U.S. Army Research and Development Lab., Ft. Monmouth, N.J.), pp. 330-353.

IRE (1961). WWV and WWVH Standard frequency and time transmission. Proc. IRE 49, 1335.

Kleppner, D., H. M. Goldenberg, and N. F. Ramsey (1962a). Properties of the hydrogen maser, Appl. Optics 1, 55.

Kleppner, D., H. M. Goldenberg, and N. F. Ramsey (1962b). Theory of the hydrogen maser, Phys. Rev. 126, 603.

McCoubrey, A. (1960). Missileborn atomichron frequency standard, Proc. 14th Annual Symp. Frequency Control (U.S. Army Research and Development Lab., Ft. Monmouth, N.J.), pp. 315-327.

McCoubrey, A. O. (1961). Frequency control by microwave atomic resonance, Microwave J. 4, 65-73.

Marcuse, D. (1962). Hydrogen cyanide molecular beam-type maser, IRE Trans. Instr. I-11, 187-190.

Marcuse, D. (1961). Maser oscillation from HCN maser at $88.6 \mathrm{kMc} / \mathrm{s}$, Proc. IRE 49, $1706-7$.

Marcuse, D. (1961). Stimulated emission from HCN gas maser observed at $88.6 \mathrm{kMc}$, J. Appl. Phys. 32, 743.

Markowitz, W. (1962). The atomic time scale, IRE Trans. Instr. I-11, 239-242.

Markowitz, W. (1962). Time measurement techniques in the microsecond region, The Engineers Digest No. 135, p. 9.

Markowitz, W., and R. G. Hall (1961). Frequency control of NBA on an international system, Proc. 15th Annual Symp. Frequency Control (U.S. Army Research and Development Lab., Ft. Monmouth, N.J.), pp. 168-179.

Merrill, F. G. (1960). Frequency and time standards. A status report, IRE Trans. Instr. I-9, 116-120.

Mizushima, M. (1962). Theory of resonance frequency shifts due to the radiation field, Proc. 16th Annual Symp. Frequency Control (U.S. Army Research and Development Lab., Ft. Monmouth, N.J.), pp. 267-286.

Mockler, R. C., and R. Beehler (1960). NBS atomic frequency standards, Proc. 14th Annual Symp. Frequency Control (U.S. Army Research and Development Lab., Ft. Monmouth, N.J.), pp. 298-309.

Mockler, R. C. (1961). Atomic beam frequency standards, in Advances in Electronics and Electron Physics Vol. 15, L. Marton, ed. (Academic Press, Inc., New York, N.Y.), pp. $1-71$.

Mockler, R. C., R. E. Beehler, and C. S. Snider (1960). IRE Trans. Instr. I-9, 120-132.
NBS (1940). Standard frequencies and time signals from NBS stations WWV and WWVH, NBS Mise. Publ. 326. Newman, J., L. Fey, and W. R. Atkinson (1963). A comparison of two independent atomic time scales, Proc. IEEE 51, 498.

Packard, M. E. (1962). The optically pumped rubidium vapor frequency standard, IRE Trans. Instr. I-11, 215223.

Penselin, S., T. Moran, V. W. Cohen, and G. Winkler (1961) Precision measurements of hfs of stable $\mathrm{Rb}$ isotopes by atomic beams, Bull. Am. Phys. Soc. 6, 513.

Peter, M., H. G. R. Venkates, and M. W. P. Strandberg (1960). Molecular trajectories in electric fields and state selection in a beam of sodium, J. Appl. Phys. 31, 693-696.

Pierce, J. A. (1960). The GBR experiment: A transatlantic frequency comparison between cesium-controlled oscillators, Proc. 14th Annual Symp. Frequency Control (U.S. Army Research and Development Lab., Ft. Monmouth, N.J.), pp. 267-274.

Ramsey, N. F., and K. Kleppner (1962). The atomic hydrogen maser, IRE Trans. Instr. I-11, 177-182.

Rarity, J., L. Saporta, and G. Weiss (1961). The Effects of Frequeney Multipliers on the Uncertainty of a Frequency Measurement. U.S. Army Research and Development Lab., Ft. Monmouth, N.J., pp. 261-277.

Reder, F., P. Brown, G. Winkler, and C. Bickart (1961). Final results of a world-wide clock synchronization experiment (Project WOSAC), Proc. 15th Annual Symp. Frequency Control (U.S. Army Research and Development Lab., Ft. Monmouth, N.J.), 226.

Reder, F. H., and C. J. Bickart (1960). Advantage of a cascaded-cavity $\mathrm{NH}_{3}$ maser over the single cavity maser, Rev. Sci. Instr. 31, 1164-1165.

Reder, F. H., and G. M. R. Winkler (1960). Preliminary flight tests of an atomic clock in preparation of long-range clock synchronization experiments, Nature 186, 592-593.

Rey, T. J. (1961). APC with pulse reference, Proc. 15th Ännual Symp. Frequency Control (U.S. Army Research and Development Lab., Ft. Monmouth, N.J.), 278-281.

Richardson, J. M., R. E. Beehler, R. C. Mockler, and R. L. Fey (1962). Les Étalons Atomiques de Fréquence au N.B.S. Comité Consultatif pour la Définition de la Seconde aupres du Comité International des Poides et Mesures, $2^{\mathrm{e}}$ session-1961 (Gauthier-Villars and Cie, Paris), pp. $57-67$.

Sachs, R. H. (1962). Theory of timekeeping in space, Proc. 16th Annual Symp. Frequency Control (U.S. Army Research and Development Lab., Ft. Monmouth, N.J.), pp. $250-255$.

Saporta, L., and G. Weiss (1962). The effects of noise on oscillator frequency stability, Proc. 16th Annual Symp. Frequency Control (U.S. Army Research and Development Lab., Ft. Monmouth, N.J., pp. 439-447.

Shirley, Jon H. (1963). Some causes of resonant frequency shifts in atomic beam machines. I. Shifts due to other frequencies of excitation, J. Appl. Phys. 34, No. 4, 783-788. Shirley, Jon H. (1963). Some causes of resonant frequency shifts in atomic beam machines. II. The effect of slow frequency modulation on the Ramsey line shape, J. Appl. Phys. 34, No. 4, 789-791.

Stone, R. R., Jr. (1962). Synchronization of local frequency standards with VLF transmissions, proc. 16th Annual Symp. Frequency Control (U.S. Army Research and Development Lab., Ft. Monmouth, N.J.), pp. 227-240.

Stone, R.R., Jr., W. Markowitz, and R. G. Hall (1960). Time and frequency synchronization of Navy VLF transmissions, IRE Trans. Instr. I-9, 155-161.

Sykes, R. A., W. L. Smith, and W. J. Spencer (1962). Performance of precision quartz crystal controlled frequency generators, IRE Trans. Instr. I-11, 243-247.

Townes, C. H. (1960). Sensitivity of microwave spectrometers using maser techniques, Phys. Rev. Letters 5, $428-430$.

Venkates, H. G., and M. W. P. Strandberg (1960). Operating characteristics of a molecular beam maser, J. Appl. Phys. 31, 396-399.

Vessot, R. F. C., and H. E. Peters (1963). Design and 
performance of an atomic hydrogen maser, IRE Trans. Instr. I-11, 183-187.

Vonbun, F. O. (1960). Fused silica cavity for a maser oscillator, Rev. Sci. Instr. 31, 900-902.

Watt, A. D., R. W. Plush, W. W. Brown, and A. H. Morgan (1961). World wide VLF standard-frequency and time signal broadcasting, J. Res. NBS 65D, 617-627.
Winkler, G. (1960). A superior atomic clock for continuous long time operation, Proc. 14th Annual Symp. Frequency Control (U.S. Army Research and Development Lab., Ft. Monmouth, N.J.).

Winkler, G., and F. Reder (1960). Preliminary results on Project WOSAC, Proc. 14th Annual Symp. Frequency Control (U.S. Army Research and Development Lab., Ft. Monmouth, N.J.), pp. 254-260.

\title{
2. $\mathrm{RF}$ and Microwave Power Measurements
}

\author{
G. F. Engen and N. T. Larsen \\ National Bureau of Standards, Boulder, Colo.
}

Several contributions in the field of radiofrequency and microwave power measurement have been made since the last General Assembly. Both advances in existing techniques and entirely new approaches can be listed. These contributions fall naturally into the general categories of bolometric, calorimetric, and miscellaneous techniques. They are presented in this order.

Recently developed commercial bolometer bridges offer higher accuracies than have been available previously. Temperature-compensated and temperature-controlled mounts are now available from several manufacturers to cover the spectrum from $10 \mathrm{Mc} / \mathrm{s}$ to $40 \mathrm{Gc} / \mathrm{s}$. Temperature coefficients of $2 \mu \mathrm{w} /{ }^{\circ} \mathrm{C}$ and resolutions of $0.5 \mu \mathrm{w}$ are typical. Both manual and self-balancing types [Pramann, 1961] are represented.

Studies of superconducting and carbon disk bolometers at liquid helium temperatures continue [Lalevic, 1960 and 1961]. Such devices have possible applications in power measurement to $10^{-15} \mathrm{~W}$.

A self-balancing d-c bridge for low-level power measurement was described [Reisener and Birx, 1962]. Alternate pulses of the unknown of and d-c are applied to the bolometer. An a-c amplifier and synchronous detector comprise a null detector to give a sensitivity of $3 \times 10^{-10} \mathrm{~W}$.

An improved technique for determining bolometer mount efficiency by impedance measurements was developed at the National Bureau of Standards [Engen, 1961]. An accuracy of \pm 0.5 percent is possible. The theory was verified by comparison with calorimetric methods, and a limit can now be set on the magnitude of the d-c-rf substitution error. An analysis of a previously unrecognized source of substitution error in dual-element coaxial bolometer mounts was investigated and reported [Engen, 1962].

An adaption of the impedance method has allowed better measurement accuracy in the $1-\mathrm{mm}$ region. The use of bolometric methods was extended to the measurement of low-pulse power at wavelengths less than $1 \mathrm{~mm}$ [Miller, Szente, and Mallory, 1963].

The introduction of thermoelectric power detectors using semiconductor materials is an innovation in the microwave field. Two such devices are now commercially available from one manufacturer under the trade names of "Bolomistor" and "Calorimistor." The "Bolomistor" is essentially a lead telluride thermocouple mounted in a standard crystal case. A 50-db range of square-law response is claimed. Time constant is about $1 \mu$ sec. The "Calorimistor" is an in-line microwave wattmeter with an insertion loss of $0.1 \mathrm{db}$ and a maximum power rating of $250 \mathrm{w}$.

Investigations of the application of thin-film thermocouples has resulted in the development of another microwave power-measuring device of the thermoelectric type [Hopfer, Riederman, and Nadler, 1962]. It is expected that these units will also be available commercially in the near future.

A temperature-compensating accessory unit for use with the National Bureau of Standards selfbalancing d-c bolometer bridge was developed. It affords about three orders of magnitude reduction in the effect of mount temperature fluctuations and may be used with unselected barretters or thermistors.

Advances have been made in commercially available dry calorimeters to improve the response time, and a simple, in-line calorimeter for monitoring high average levels was developed [Brady, 1962]. A flow type calorimeter with a limit of error of \pm 1 percent $+0.1 \mathrm{w}$ from 30 to $1000 \mathrm{w}$ is now commercially available [Vinding, 1961].

A new 12.4 to $18.0 \mathrm{Gc} / \mathrm{s}$ microcalorimeter has been completed at the National Bureau of Standards and is now in use for routine calibrations. The new microcalorimeter is similar in design to the original 8.2 to $12.4 \mathrm{Gc} / \mathrm{s}$ model [Engen, 1959] with some refinements added. 
A novel method of measuring peak pulse power density was reported at the 1962 International Conference on Precision Electromagnetic Measurements [White, 1962]. The system consists of an energyabsorbing surface coupled mechanically to an elastic wave sensor and an indicator. Thermal expansion produces an elastic wave much more efficiently than radiation pressure.

Two similar systems for the measurement of microwave pulse power by means of sampling techniques were reported at the 1962 ICPEM. One system [Denney, Mavis, and Still, 1962] uses a coherent detector to compare sample levels from unknown and standard sources. The other system [Hudson, Ecklund, and Ondreika, 1962] utilizes a fast solidstate coaxial switch to perform the sampling. Accuracies of \pm 3 percent are possible, and the two systems together cover the range from $-60 \mathrm{dbm}$ to $70 \mathrm{dbm}$.

A method of power measurement depending on the acceleration experienced by electrons in a beam traversing an evacuated waveguide is still under development at the National Bureau of Standards. Errors due to the spread in energies of emitted electrons are larger than anticipated, but may be solved by audio substitution methods. Development of a high-power stirred-water calorimeter for the 8.2 to $12.4 \mathrm{Gc} / \mathrm{s}$ band continues at the National Bureau of Standards.

Two methods of evaluating the efficiency of waveguide-to-coaxial adaptors have been developed theoretically at the National Bureau of Standards. This approach may permit the use of waveguide bolometer mounts to calibrate coaxial power standards, and offers a solution to the difficulty in evaluating coaxial bolometer mount efficiencies directly.

The international intercomparison of microwave power standards has been extended to lower frequencies as recommended by the XIIIth General Assembly. At a frequency of $300 \mathrm{Mc} / \mathrm{s}$, the United States and the United Kingdom standards were found to agree within 0.5 percent [NBS Tech. News Bull. 46 40, Mar. 1962]. In a comparison with Japan at $400 \mathrm{Mc} / \mathrm{s}$, a nominal difference of 2 percent was observed.

Some progress has also been realized in resolving the 1 to 2 percent difference which existed between the U.S. and U.K. X-band standards at the time of the last General Assembly. Additional measurements are planned for this frequency region.

\section{References}

Brady, M. M. (1962), In line waveguide calorimeter for highpower measurement, IRE Trans. MTT-10, 359.

Denney, G. A., C. L. Mavis, and C. J. Still (1962), Microwave pulse-power measurements, IRE Trans. Instr. I-11, 3 and 4.

Engen, G. F. (1959), A refined $X$-band microwave microcalorimeter, J. Res. NBS 63C, No. 1, $77-82$

Engen, G. F. (1961), A bolometer mount efficiency measurement technique, J. Res. NBS 65C, No. 2, 113-124.

Engen, G. F. (Oct. 15-17), The DC-RF substitution error in power measurements which use series-parallel connected bolometers, 1962 Joint Meeting URSI, Ottawa, Canada.

Hopfer, S., N. H. Riederman, and L. Nadler (1962), The properties of thermo electric elements as microwave power detectors, IRE Conv. Rec. 9, Pt. 3, 77.

Hudson, P. A., W. L. Ecklund, and R. A. Ondreika (1962), Measurement of $\mathrm{RF}$ peak pulse power by a samplingcomparison method, IRE Trans. Instr. I-11, Nos. 3 and 4 .

Lalevic, Bogoljub (1960), Criteria for the choice of a superconducting bolometer, J. Appl. Phys. 31, No. 7, 1234-1236.

Lalevic, Bogoljub (1962), Carbon resistor as a bolometer for lower power RF signals, Rec. Sci. Instr. 33.

Miller, R. H., P. A. Szente, and K. B. Mallory (1963), A measurement of bolometer mount efficiency at millimeter wavelengths, IEEE Trans. MTT-11, No. 5.

Pramann, R. F. (1961), Thermal drift in microwave power meters, Electron. Ind. 20, No. 11.

Reisener, W. C., and D. L. Birx (1962), A new precision low level bolometer bridge, Proc. IRE 50, No. 1.

Vinding, Jorgen P. (1961), An accurate calorimeter for high microwave power, Microwave J. 4, No. 1.

White, R. M. (1962), An elastic wave method for the measurement of pulse-power density, IRE Trans. Instr. I-11, Nos. 3 and 4 . 


\title{
3. Standards and Measurements of Attenuation, Imped- ance, and Phase Shift
}

\section{Period Covered: September 1960-December 1962}

\author{
R. W. Beatty \\ National Bureau of Standards, Boulder, Colo.
}

\subsection{Attenuation Standards and Measure- ments}

Standards

At the lower frequencies, particularly in the audiofrequency range, the inductive voltage divider or ratio transformer serves as an accurate standard. The voltage ratios are so close to their nominal values that the problem of calibrating this type of standard has been a challenging one. Refined equipment developed in 1960 permitted the 10 to 1 ratio to be determined to $\pm 4 \times 10^{-9}$ with a 50 percent confidence interval [Cutkosky and Shields, 1960]. By 1962, refined methods of calibrating inductive voltage dividers or ratio transformers had been developed having a routine measurement accuracy within \pm 0.0000002 in voltage ratio [Zapf, 1962].

At higher frequencies, especially at $30 \mathrm{Mc} / \mathrm{s}$, the below cutoff waveguide piston attenuator continued to be used as a standard although ways were devised to avoid the loss in dynamic range caused by the 20 to $30 \mathrm{db}$ residual loss of this type of standard. In one case, a high-powered, water-cooled launching coil was designed to excite the correct mode in the standard attenuator [Allred and Cook, 1960].

At microwave frequencies, both audio and $\mathrm{IF}$ substitution techniques permitted use of the above types of attenuation standards, but above approximately $2.6 \mathrm{Gc} / \mathrm{s}$, serious consideration was given to the rotary vane type of attenuator as a standard. The use of this type of attenuator as a calculable standard still awaits complete evaluation of all sources of error, but some progress was made in the investigation of certain types of errors. An analysis of error caused by imperfect knowledge of the angular position of the vane was described. Experimental confirmation of the analysis was obtained using an attenuator which had been modified to greatly increase the resolution [Larson, 1962].

A refined rotary vane type of attenuator was constructed in another attempt to analyze and reduce errors from various sources. An accuracy of $0.02 \mathrm{db}$ per $10 \mathrm{db}$ was estimated for this attenuator [James, 1962].

\section{Measurements}

The calibration of a resistive voltage divider at d-c, which is used in turn to calibrate other voltage dividers, was described [Morgan and Riley, 1960]. The divider could then be used for part-per-million ratio measurements.

Ratiometric measurements using ratio transformers at audiofrequencies were briefly summarized [Widenor and Hermon, 1962].

An accurate loss and phase shift measuring apparatus was developed for the range $10-300 \mathrm{kc} / \mathrm{s}$. Estimated error limit for insertion loss measurements is $\pm 0.002 \mathrm{db}$. Mercury relays operating at $13 \mathrm{c} / \mathrm{s}$ facilitate rapid comparison of the unknown with the carbon film standard attenuator [Elliott, 1962].

Operating in the frequency range 5 to $250 \mathrm{Mc} / \mathrm{s}$, another loss and phase shift measuring apparatus was developed. It also employs rapid switching and heterodyned all signals to $1 \mathrm{Mc} / \mathrm{s}$, the operating frequency of the carbon film attenuation standard. The estimated error limit is $\pm 0.1 \mathrm{db}$ [Leed and Kummer, 1961].

Refinements and applications of known techniques continued at the higher frequencies, resulting in wider ranges and increased accuracies, the total error in the range from 130 to $140 \mathrm{db}$ estimated to be $\pm 0.068 \mathrm{db}$ [Allred and Cook, 1960]. The parallel IF substitution technique was again used at microwave frequencies to avoid the loss in dynamic range of attenuation measurements normally caused by the 20 to $30 \mathrm{db}$ residual loss of below-cutoff waveguide piston attenuators [Weinschel, 1961].

Another so-called "self-calibration" technique was developed and applied to the checking of a belowcutoff waveguide piston attenuator, obtaining good agreement with the calculated attenuation rate [Peck, 1962].

A modulated subcarrier technique for measuring microwave attenuation was developed [Schafer and Bowman, 1962]. This technique has the advantage of requiring only one microwave source (no local oscillator required) while retaining the large dynamic range of the IF substitution technique. In addition, it permits the use of relatively inexpensive inductive voltage divider or ratio transformer types of attenuation standards. A further advantage is that the phase shift of the attenuator under test may be determined with the same system and at the same time that the attenuation measurement is made. The resolution is high $(0.0001 \mathrm{db}$ at 0.01 
$\mathrm{db}$ ), and the accuracy is comparable with both d-c and IF substitution systems of the highest quality.

Routine calibrations of coaxial attenuators at the National Bureau of Standards are performed over the frequency range 0.3 to $5.6 \mathrm{Gc} / \mathrm{s}$, and attenuators in rectangular waveguide systems are calibrated from 2.6 to $26.5 \mathrm{Gc} / \mathrm{s}$, using IF substitution techniques. The conservatively estimated limits of error are for fixed pads, coaxial: $\pm 0.2 \mathrm{db}$ or 1 percent of the attenuation in decibels, whichever is greater; and rectangular waveguide: $\pm 0.1 \mathrm{db}$ or 1 percent of the attenuation in decibels, whichever is greater. For incremental attenuation measurements on variable attenuators, the corresponding limits are coaxial: $\pm 0.1 \mathrm{db}$ or 1 percent of the attenuation change in decibels, whichever is greater; and rectangular waveguide: $\pm 0.05 \mathrm{db}$ or 0.5 percent of the attenuation change in decibels, whichever is greater [Larson, 1961].

The attenuation of circular waveguide was measured at 33 to $90 \mathrm{Gc} / \mathrm{s}$ by a shuttle-pulse technique in which the pulse made 20 to 30 round trips in the waveguide before being detected. An ingenious circuit permitted the same oscillator to serve as signal source and local oscillator for the receiver [King and Mandeville, 1961].

At millimeter waves, conventional techniques for measuring attenuation at lower frequencies are applicable, and rapid comparison switching offers some advantages [Chasek, 1962].

\section{References}

Allred, C. M., and C. C. Cook [Sept. 1960], A precision rf attenuation calibration system, IRE Trans. Instr. I-9, No. 2, 268-274

Chasek, M. B. [Nov. 1962], An accurate millimeter wave loss and delay measurement set, IRE Trans. MTT-10, No. 6, $521-527$.

Cutkosky, R. D., and J. Q. Shields [Sept. 1960], The precision measurement of transformer ratios, IRE Trans. Instr. I-9, No. 2, 243-250.

Elliott, J. S. [Sept. 1962], A high-precision direct-reading loss and phase measuring set for carrier frequencies, Bell Syst. Tech. J. 41, No. 5, 1493-1517.

James, A. V. (Sperry Gyroscope Co., Great Neck, N.Y.) [1962], A high-accuracy microwave-attenuation standard for use in primary calibration laboratories, presented 17 Aug. 1962, at the International Conference on Precision Electromagnetic Measurements at NBS, Boulder, Colo. (Papers from this conference published in the Dec. 1962 issue of the IRE Trans. on Instrumentation.)

King, A. P., and G. D. Mandeville [Sept. 1961], The observed 33 to $90 \mathrm{kMc}$ attenuation of two-inch improved waveguide, Bell Syst. Tech. J. 40, No. 5, 1323-1330.

Larson, R. E. [May 1962], Microwave measurements in the NBS Electronic Calibration Center, Proc. IEE (London) 109, Part B, Supplement No. 23, 644-650.

Larson, Wilbur [1962], Analysis of rotation errors of a waveguide rotary vane attenuator, 1962 IRE International Convention Record, Part 3, 213-219.

Leed, D., and O. Kummer [May 1961], A loss and phase set for measuring transistor parameters and two port networks between 5 and $250 \mathrm{Mc} / \mathrm{s}$, Bell Syst. Tech. J. 40, No. 3, 841-884.

Morgan, M. L., and J. C. Riley [Sept. 1960], Calibration of a Kelvin-Varley standard divider, IRE Trans. Instr. I-9, No. 2, 237-243.

Peck, R. L. [Jan.-Mar. 1962], A method for the self-calibra- tion of attenuation-measuring systems, J. Res. NBS $66 \mathbf{C}$, No. $1,13-18$

Schafer, G. E., and R. R. Bowman [May 1962], A modulated sub-carrier technique of measuring microwave attenuation, Proc. IEE (London) 109, Part B, Suppl. No. 23, 783-786. Weinschel, B. O. [Sept. 1961], An accurate attenuation measuring system with great dynamic range, Microwave $J$. 4, No. 9, 77-83.

Widenor, Malcolm D., and Sidney Hermon [Mar. 23, 1962], Ratiometric measurements: techniques and accuracies, Electronics $\mathbf{5 6}, 58$.

Zapf, T. L. [Jan.-Mar. 1962], Voltage ratio measurements with a transformer capacitance bridge, J. Res. NBS 66C, No. 1, 25-32.

\subsection{Impedance Standards and Measurements}

\section{Standards}

The NBS Unit of Resistance was reevaluated by comparison with an improved computable cross capacitor of the Thompson-Lampard type. The NBS unit of resistance was determined to be 1.0000023 ohms \pm 2.1 parts per million. An angular frequency of $\omega=10,000$ was used in the comparisons [Cutkosky, 1961].

At audiofrequencies, the calibration of inductance standards was described [Zapf, 1961].

The mutual inductance analog of the generalized Thompson-Lampard theorem was developed, and the advantages of an eight-wire cage were discussed [Page, 1962].

The development of coaxial line capacitance standards was continued [Jones, 1962; Selby, 1962].

At microwave frequencies, the design and construction of quarter-wavelength short-circuit reflection coefficient standards for coaxial line were described [Beatty and Anson, 1962].

\section{Coaxial Connectors and Waveguide Joints}

In connection with impedance measurements in coaxial systems, some very significant work was done in the design and development of high precision coaxial connectors. Connectors were produced for coaxial line of $\mathrm{IDOC}=0.5625$ in., and $\mathrm{ODIC}=0.2442$ in., which had a VSWR of less than 1.003 over the frequency range from 0 to $8 \mathrm{Gc} / \mathrm{s}$ [Sanderson, 1962]. This represents perhaps an order of magnitude decrease in the reflections from coaxial connectors operating over this frequency range. It is expected that this development will help usher in a period of advances in the state of the art in microwave measurements in coaxial systems.

The importance of coaxial connectors in VSWR measurements was well illustrated in a comprehensive summary article [Sweet and Lebowitz, 1961].

A technique to measure small reflections from coaxial connector pairs with a slotted line was developed [Sanderson, 1961]. In this method, a response curve for the slotted line was first obtained using a tuned load. Then a half-wavelength section of air line was inserted between the slotted line and the load and another response curve was obtained. Subtraction of one response curve from the other 
gave a standing wave pattern essentially free from effects of line and probe coupling irregularities, and indicative of the reflection from the connectors. The technique gave both magnitude and phase information and was useful in the above development of high-precision coaxial connectors.

A variation on the width of the minimum technique for slotted line measurement of VSWR was developed [Nunn, 1961]. Although both this technique and the one described immediately above were called substitution methods, they had little in common, and differed both in what was substituted, and the way in which it was substituted.

Leakage from coaxial cables and connectors was analyzed and studied experimentally. The leakage energy was confined by a triaxial line and load, resonated to yield maximum output. The method is valid to measure relative leakage, but since leakage depends to some extent on the state of things external to the transmission line, it is difficult to determine a realistic value for absolute leakage [Zorzy and Muehlberger, 1961].

A sensitive method using a tuned, single-directional coupler and sliding terminations was developed to measure reflections and losses from waveguide joints [Beatty, Engen, and Anson, 1960]. Measurements were made of the reflection from deliberately misalined joints in rectangular waveguide, comparing with calculated curves. The method is also applicable to coaxial connectors and has been used to check the above high-precision coaxial connectors, obtaining close agreement with the substitution method [Jickling, 1962].

The reflection from the junction of two rectangular waveguides, one having square inside corners, and the other having rounded or filleted inside corners, was investigated analytically and experimentally [Anson, Beatty, Kerns, and Grandy, 1962].

The use of short pulses to detect reflections from discontinuities on transmission lines received further attention. Use was made of a sampling oscilloscope and a pulse generator having a rise time of 0.5 nanosecond [Halverson, 1961].

The measurement of small reflections in rectangular waveguide systems, especially at waveguide joints was discussed, with special emphasis on the use of a hybrid junction and sliding termination. The residual equivalent return loss was defined and uncertainties in its measurement were discussed [Pomeroy, 1962].

\section{Impedance Measurement Techniques}

An improved technique for establishing resistance ratios for the precise comparison of standard resistors was described [Pailthorp and Riley, 1962]. The audiofrequency ratio transformer bridge for standardization of inductors and capacitors made possible fuller utilization of the accuracy of certified standards [Hillhouse and Kline, 1960]. The application of series resonance techniques to the ratio transformer bridge resulted in a resonance capacitance-toinductance transfer accuracy better than $50 \mathrm{ppm}$ [Hillhouse, 1961].
A further description of tuned reflectometer techniques with information useful in error analysis was given [Anson, 1961]. A method was developed for measuring the impedance of a load that varies with time, provided that the variation can be repeated periodically, at an audio rate for example. Basically, the familiar width of minimum method was used to measure the VSWR with a slotted line [Iizuka, 1962]. A sweep voltage was used to measure changes in capacitances of varactor diodes [Jasinski, 1962]. Another bridge was developed for the visual display of complex reflection coefficient [Strandberg, 1961].

A conductance analyzer was developed for use in the analysis of nonlinear devices [Conn, 1962].

A routine calibration service for reflection coefficient magnitude or VSWR standards was offered by NBS, Boulder, Colo., for WR-90 (X-band) rectangular waveguide systems. The limits of error in the measurement of reflection coefficients having magnitudes from 0.025 to 0.1 are \pm 1.5 percent, and from 0.1 to $1.0, \pm 1$ percent, conservatively estimated [Larson, 1961].

Conventional microwave bridge techniques for impedance measurement have been found applicable at a frequency of $150 \mathrm{Gc} / \mathrm{s}$ [Thaxter, 1962].

A bridge was developed to measure the mutual impedance between antennas. It is especially helpful with large planar arrays [Rupp, 1962].

\section{Impedance Measurements Associated with Networks}

The transformation of impedances by lossless networks continued to receive attention [Dawirs, 1961]. The precision measurement of microwave networks was summarized and methods of measuring arbitrary linear 2-ports were given [Altschuler, 1961]. The measurement of active and nonreciprocal 2-ports using an interference bridge was described. Using slotted lines, circular loci of reflection coefficients were obtained from point-by-point measurements. All four of the scattering coefficients of a 2-port can be obtained by this technique [Altschuler, 1961].

\section{References}

Altschuler, H. M. (1962), The measurement of arbitrary linear microwave two-ports, Proc. IEE (London) 109, Part B, Supplement No. 23, 704-712.

Altschuler, H. M. (1962), The precision measurement of microwave networks, Proc. IEE (London) 109, Part B, Supplement No. 23, 686-692.

Anson, W. J. (Oct.-Dec. 1961), A guide to the use of the modified reflectometer technique of VSWR measurement, J. Res. NBS 65C, No. 4, 217-223.

Anson, W. J., R. W. Beatty, D. M. Kerns, and W. T. Grandy (1962), Investigations of the reflection from a junction of an ideal rectangular waveguide with one having rounded inside corners, paper 3.2 , presented on May 22, 1962 at the PGMTT National Symposium, Boulder, Colo.

Beatty, R. W., and W. J. Anson (July 1962), Application of reflectometer techniques to accurate reflection measurements in coaxial systems, Proc. IEE (London) 109, Part B, No. 46, 345-348.

Beatty, R. W., G. F. Engen, and W. J. Anson (Sept. 1960), Measurement of reflections and losses of waveguide joints and connectors using microwave reflectometer techniques, IRE Trans. Instr. I-9, No. 2, 219-226.

Conn, M. L. (Sept. 1962), The conductance analyzer, IRE Trans. Instr. I-11, No. 2, 71-75. 
Cutkosky, Robert D. (May-June 1961), Evaluation of the NBS unit of resistance based on a computable capacitor, J. Res. NBS 65A, No. 3, 147-158.

Dawirs, Harvel N. (Oet. 1961), A simple method of transforming impedances through a lossless network, Microwave J. 4, No. 10, 86-90.

Halverson, H. (June 30, 1961), Testing microwave transmission lines using the sampling oscilloscope, Electronics 34, No. 26, 86-88.

Hillhouse and Kline (Sept. 1960), A ratio transformer bridge for standardization of inductors and capacitors, IRE Trans. Instr. I-9, No. 2, 251-257.

Hillhouse, D. L. (1962), Resonant capacitance-inductance transfer using the ratio transformer bridge, paper No. CP62-254, available from A.I.E.E., 345 E. 47 th St., New York 17, N.Y.

Iizuka, K. (Nov. 1962), A method of measuring the timedependent impedance of the load, Microwave J. 5, No. 11, $86-91$

Jasinski, W. (Mar. 9, 1962), Measuring capacitance of varactor diodes dynamically, Electronics 35, No. 9, 60-61.

Jickling, R. M. (June 29, 1962), Meeting on high precision connectors, NBS Report No. 7277.

Jones, Raymond N., and Robert E. Nelson (1962), The role of capacitance in the National Reference Standards for high frequency impedance, presented Oct. 16, 1962 at 17 th Annual Instrument-Automation Conference and Exhibit, New York, N.Y., paper No. 18.1.62, Instrument Society of America Session Reprint Compilation, Session 18. Precision Capacitance Measurements.

Larson, R. E. (1962), Microwave measurements in the NBS Electronic Calibration Center, Proc. IEE (London) 109, Part B, Supplement No. 23, 644-650.

Nunn, W. M. (Oct. 1961), Substitution method of measuring standing-wave ratio, Rev. Sci. Instr. 32, No. 10, 1106-1110.

Page, Chester H. (Jan.-Mar. 1963), A new type of computable inductor, presented (Oct. 17, 1962) at the joint meeting of the Canadian and U.S.A. Groups of URSI at Ottawa, Canada. J. Res. NBS 6\%B, No. 1 31-39.

Pailthorp, R. M., and J. C. Riley (1962), An improved technique for establishing resistance ratios, paper 10.1.62, 17th Annual Instrument-Automation Conference and Exhibit, (15 to 18 Oct., 1962) New York, N.Y., Instrument Society of America Session Reprint Compilation, Session 10. Electrical Measurement Standards.

Pomeroy, Allen F. (Nov. 1962), Evaluation of uncertainties in measurement of electrical echoes in waveguide lines, Microwave J. 5, No. 11, 72-77.

Rupp, William E. (Aug. 1962), Antenna mutual impedance bridge, Microwave J. 5, No. 8, 95-98

Sanderson, A. E. (Nov. 1961), A new high-precision method for the measurement of the VSWR of coaxial connectors, IRE Trans. MTT, MTT-9, No. 6, 524-528.

Sanderson, A. E. (Jan. 1962), An accurate substitution method of measuring the VSWR of coaxial connectors, Microwave J. 5, No. 1, 69-73.

Selby, M. C. (Apr. 6, 1962), Analysis of coaxial two-terminal conical capacitor, NBS Mono. 46.

Strandberg, M. W. P. (June 1961), Linear, complex-reflection coefficient bridge, Microwave J. 4, No. 6, 66-73.

Sweet, L., and R. A. Lebowitz (July 1961), Measurement of VSWR in coaxial svstems, PRD Repts. \%, No. 3.

Thaxter, J. B. (Dec. 1962), Microwave measurements at $150 \mathrm{Gc} / \mathrm{s}$, IRE Trans. Instr. I-11, No. 3.

Zapf, T. L. (July-Sept. 1961), Calibration of inductance standards in the Maxwell-Wien bridge circuit, J. Res. NBS 65C, No. 3, 183-188.

Zorzy, John, and R. F. Muehlberger (Nov. 1961), Rf leakage characteristics of popular coaxial cables and connectors, $500 \mathrm{Mc}$ to $7.5 \mathrm{Gc}$, Microwave J. 4, No. 11, 80-86.

\section{3. Phase Shift Standards and Measurements}

\section{Standards}

A continuously variable phase shifter using L-C pi sections was developed at NBS for operation at
$400 \mathrm{c} / \mathrm{s}$. The error limit was estimated to be 0.01 $\mathrm{deg}$, and the upper frequency limit for this type of phase shifter was estimated to be approximately $20 \mathrm{kc} / \mathrm{s}$ [Park and Cones, 1960].

A phase-measuring set operating from 10 to 300 $\mathrm{kc} / \mathrm{s}$ heterodynes all signals to a lower frequency at which phase detection is based upon measurement of time interval corresponding to displacement of sine wave zero crossings by the unknown [Elliott, 1962]. An accuracy of $\pm 0.02 \mathrm{deg}$ is estimated.

Spirally wound delay lines can be used as continuously variable phase shifters between $100 \mathrm{kc} / \mathrm{s}$ and $15 \mathrm{Mc} / \mathrm{s}[\mathrm{Yu}, 1961]$.

A phase-measuring set operating from 5 to 250 $\mathrm{Mc} / \mathrm{s}$ heterodynes all signals to $1 \mathrm{Mc} / \mathrm{s}$, where the phase standard used is a continuously variable four-quadrant sine capacitor of high quality and permanence [Leed and Kummer, 1961].

At microwave frequencies, the terminated slotted line continues to be a convenient standard of phase shift where high accuracy is not required [Zacharias, 1961].

Phase discriminators employing waveguide hybrid junctions are used to measure phase difference between two signals [Cohn and Oltman, 1961].

The error analysis was completed for a standard phase shifter consisting of the combination of sliding short-circuit in a uniform section of rectangular waveguide connected to a tuned, single directional coupler reflectometer [Schafer and Beatty, 1960].

\section{Measurements}

At frequencies from 0.2 to $20 \mathrm{kc} / \mathrm{s}$, phase difference was measured with transistor flip-flop circuit [Woodbury, 1961].

The phase-measuring sets previously mentioned cover frequency ranges from 10 to $300 \mathrm{kc} / \mathrm{s}$ [Elliott, 1962] and 5 to $250 \mathrm{Mc} / \mathrm{s}$ [Leed and Kummer, 1961].

A review and bibliography of phase-measuring technique was given [Sparks, 1961]. This was a valuable contribution, since a detailed treatment of this subject is lacking in most microwave textbooks and the technical papers on the subject are widely distributed in the literature.

A variety of phase-measurement techniques were developed for use at microwave frequencies. A measurement system using hybrid tees with no moving parts or variable phase shifters has no ambiguities throughout $360 \mathrm{deg}$ [Kaiser, Smith, Pepper, and Little, 1962]. Swept-frequency phaseshift measurement techniques using hybrid tee circuits [Cohn, 1962] and spaced probes in a slotted line [Lacy, 1961] formed the basis for commercially available apparatus. A modulated subcarrier technique for measuring microwave phase shift, permitted high resolution and accuracy with independence from the relative levels of the two signals compared [Schafer, 1960]. An extension of a conventional method permitted measurement of differential phase shift of traveling-wave tube amplifiers or electrically variable phase shifters [Israelsen and Haegele, 1962]. 
The phase variation along a narrow pulse generated by a high-power traveling-wave tube was determined by a two-channel system and suppressed carrier technique [Sparks, 1962]. Delay at millimeter wavelengths was measured to $0.2 \mu \mathrm{sec}$ [Chasek, 1962].

The mismatch errors in a number of basic phasemeasuring methods were analyzed [Schafer, 1960].

\section{References}

Chasek, M. B. (Nov. 1962), An accurate millimeter wave loss and delay measurement set, IRE Trans. MTT-10, No. 6, $521-527$.

Cohn, S. B. (Dec. 1962), Swept phase-measurement techniques with CW and pulsed signals, IRE Trans. Instr. I-11, No. 3.

Cohn, Seymour B., and H. George Oltman (1961), A precision microwave phase-measurement system with sweep presentation, 1961 IRE International Convention Record, Pt. 3, $147-150$.

Elliott, J. S. (Sept. 1962), A high-precision direct-reading loss and phase measuring set for carrier frequencies, Bell Syst. Tech. J. 41, No. 5, 1493-1517.

Israelsen and Haegele (Apr. 1962), Technique for the dynamic measurement of differential phase shift at microwave frequencies, Proc. IRE, 50, No. 4 (correspondence section), $474-475$.

Kaiser, J. A., H. B. Smith, Jr., Wm. H. Pepper, and John H. Little (Nov. 1962), An automatic microwave phase comparator, IRE Trans. MT'T-10, No. 6, 548-550.
Lacy, Peter (1961), Analysis and measurement of phase characteristics in microwave systems, 1961 WESCON Convention Record, Paper No. 23/3.

Leed, D., and O. Kummer (May 1961), A loss and phase set for measuring transistor parameters and two-port networks between 5 and $250 \mathrm{Mc} / \mathrm{s}$, Bell Syst. Tech. J. 40, No. 3, $841-884$.

Park, J. H., and H. N. Cones (July-Sept. 1960), Phase-angle master standard for 400 cycles per second, J. Res. NBS 64C, No. 3, 229-240.

Schafer, G. E. (Sept. 1960), A modulated subcarrier technique of measuring microwave phase shifts, IRE Trans. Instr. I-9, No. 2, 217-219.

Schafer, G. E. (Nov. 1960), Mismatch errors in microwave phase shift measurements, IRE Trans. MTT-8, No. 6, $617-622$.

Schafer, G. E. and R. W. Beatty (Dec. 1960), Error analysis of a standard microwave phase shifter, J. Res. NBS $\mathbf{6 4 C}$, No. 4, 261-265.

Sparks, R. A. (June 1961), A comparative review of phase measurement methods at microwave frequencies, Proc. 5th National Convention on Military Electronics, p. 65.

Sparks, R. A. (Dec. 1962), A phase measuring system for short rf pulses, IRE Trans. Instr. I-11, No. 3.

Woodbury, J. R. (Sept. 22, 1961), Measuring phase with transistor flip-flops, Electronics 34, 56 .

Yu, Y. P. (Mar. 17, 1961), How to measure phase at high frequencies, Electronics 34, No. 11, 54-56.

Zacharias, Alfred (1961), A method for measuring the incremental phase and gain variations of a traveling wave tube, 1961 IRE International Convention Record, Pt. 3, $151-154$.

\title{
4. Pulsed and CW Sinusoidal Voltage and Current Measurements
}

\author{
M. C. Selby \\ National Bureau of Standards, Boulder, Colo.
}

This report appears to be the first URSI measurement report dealing with pulsed voltages and currents; it seems therefore advisable to state briefly the applications, parameters, and ranges involved. Pulsed voltages, pulsed currents, and pulsed power are quantities widely applied in the field of radioelectronics for many years. Their importance is on a par with continuous wave (CW) amplitude modulation techniques in transmitting intelligence via electromagnetic media and exceeds CW in applications requiring signal levels in the megawatt range. These pulsed quantities are used, for example, in radar tracking and trajectography with angular precision of fractions of milliradians at distances up to $1500 \mathrm{mi}$, navigation, radar astronomy, digital meters, telemetry, pulsed light sources, television, telephony, telegraphy, digital counters, electronic computers, particle accelerator circuitry, measurements in nuclear physics, microwave relay systems, time domain reflectometry, ignition applications, x-ray equipment, carrier pulses, etc.

Pulsed voltages may be subdivided into three general classes: (a) "direct pulses," for example, pulses consisting of a positive unit step function and a delayed negative unit step function, forming a rectangular voltage pulse; (b) rf pulses consisting of groups of sinusoidal waves unmodulated or modulated in various ways; and (c) pulses obtained by demodulating the rf pulses. The parameters to be measured in the "direct" pulses are the same as for the demodulated pulses; however, measurement conditions may be different in the two cases. The rf-pulse parameters of interest are generally different from those of the other two classes.

The following parameters and approximate ranges seem presently of interest in measuring pulses:

Amplitude average peak and along the pulse: $10^{-6}$ to $5 \times 10^{5} \mathrm{v}$.

Attenuation: $10^{-2}$ to $10^{2} \mathrm{db}$, to measure attenuations of such devices as screened rooms, radomes, guides, switches, etc.

Time intervals: $10^{-10}$ to $10^{-1}$ sec. These are needed to determine rise time, decay time, pulse duration (width), pulse spacing, pulse duty factor, computer memory time, network time response, and component (diode, switch, transistor, magnetic core, etc.) response.

Current amplitude: milliamperes to kiloamperes. $\mathrm{Gc} / \mathrm{s}$ 
Bandwidth of circuits and amplitude spectra of pulses: to about $5 \mathrm{Gc} / \mathrm{s}$.

Phase spectra and phase variations, e.g., along a narrow rf pulse: 0 to $2 n \pi(n=1,2,3$, . . . $)$.

"Jitter" (instability) of amplitude, frequency, time, and phase: over a range down to an order of magnitude lower than the low limits indicated above for the corresponding quantities.

Other parameter terms such as "overshoot," "undershoot," "droop," "ripple," and "zero reference", have been used, and still others may appear in recent publications. These will be defined when necessary.

The reader is referred to existing standards (IRE Standards, 1955) and prevalent methods of measurement. This review will be limited to progress reported in salient publications during the approximate period of 1960 to 1962 .

\subsection{Pulsed Voltage and Current}

\subsubsection{Low-Voltage Amplitudes}

The predominant tool in the measurement of pulsed voltage and pulsed current characteristics is the cathode ray oscilloscope (CRO), as it was in the past, because it displays the waveform and affords the most convenient and practical way of measuring and monitoring the pulse parameters. The CRO and associated techniques have been undergoing continuous improvement to meet the needs of nanosecond-width pulses with rise times below a nanosecond. Lewis and Wells brought the subject up to date [Lewis and Wells, 1959] in analyzing how CRO traveling wave deflection systems advanced the state of the art; the effective cutoff frequency, $f_{c}$ (defined as the frequency at which the deflection suffers a 3 -db loss), was about $2000 \mathrm{Mc} / \mathrm{s}$ at a screen spot diameter of $0.04 \mathrm{~mm}$, a deflection sensitivity of about $0.03 \mathrm{v}$ per spot width, maximum writing speed of "10 to the 11th power" spot widths per second and maximum signal of about 5 v. Less practical oscilloscopes for direct display of the waveform were developed with bandwidths up to $10 \mathrm{Gc} / \mathrm{s}$ [Lewis and Wells, 1959]. An up-to-date account is given also of the sampling technique [Carlson, Krakauer, Magleby, Monnier, VanDuzer, and Woodbury, 1959] for $f_{c}$ of about $300 \mathrm{Mc} / \mathrm{s}$. A useful survey of most practical display traveling wave oscilloscopes (TWO) was prepared [Noel and Susskind, 1961]. It discusses basic deflection structures of various systems, and points out the major shortcomings of the sampling technique; these are its limited application to recurrent pulses and to maximum peak voltage values of the order of $1 \mathrm{v}$ in order to avoid amplitude distortion; the cutoff frequency is given at about $1 \mathrm{Gc} / \mathrm{s}$ for the practical sampling systems and about $2 \mathrm{Gc} / \mathrm{s}$ for the practical TWO's with direct display.

A modified sampling technique to measure fractional nanosecond pulse characteristics was developed [Gaddy, 1960]. Conceding that the TWO and previous sampling techniques are capable of measuring pulses with rise times of 300 to 400 psec (picosecond=
$10^{-12} \mathrm{sec}$, the paper claims considerably wider eflective bandwidths with this system for approximately trapezoidal pulses. This technique, under the name of "pulse comparison technique," employs conventional CRO's. The unknown pulse is fed into two parallel identical channels, one of which has a variable delay line. The outputs of the two channels are added in a coincidence "tee" circuit consisting of a crystal diode, capacitor, and resistor coaxially assembled. The variable delay line allows a continuous relative time shifting of an identical pulse with respect to the original pulse, and the amplitude output of the coincidence circuit versus time delay is observed on an oscilloscope and plotted. The time delays corresponding to changes of slopes of this plot yield the rise, duration, and decay time intervals of the unknown pulse. The comparison system bandwidth is said to be limited only by that of the coincidence circuit and not by the width of the sampling: pulse; the bandwidth of the comparison system is stated to be at least $4 \mathrm{Gc} / \mathrm{s}$. Experimental results show measurements of rise time of the order of 300 psec at agreement with theoretical values and degree of confidence of about 30 percent. The same values measured with a TWO were of the order of 500 psec; the difference is ascribed to pulse distortion by the delay cables of the TWO and the bandwidth limitation of its deflection structure. The following: drawbacks of the technique are indicated by the author: (a) as described, it is useful only for trapezoidal shape pulses; it can be applied to other shapes but these shapes as well as the shapes of the output curves must be known in advance; (b) the estimated bandwidth of the comparison system had a rise time limitation of the order of $100 \mathrm{psec}$; (c) the system does not furnish a display of the pulse that is being measured; and (d) point-by-point measurements must be taken with great care.

A useful summary of practical problems associated with nanosecond pulse measurement was presented [Winnigstad, 1961]. The need for a standard source of pulses and for sinusoidal voltages over a frequency range to a few gigacycles that is constant to better than $+0.025 \mathrm{db}$ was emphasized. Noveldesign peak voltmeters were noted in two cases for relatively wide pulses [Lang, 1961; Mackenzie, 1960].

\subsubsection{High-Voltage Amplitudes}

There appear to be no publications in the current periodicals during the last 3 years on the subject of measuring megawatt pulses with rise times and durations of the order of a nanosecond or bandwidth requirement in the gigacycle range. Yet progress has been apparently made. Thus, for example [Varian Associates, 1962], a present capability is indicated of over $10 \mathrm{Mw}$ peak at frequencies up to $300 \mathrm{Mc} / \mathrm{s}$ and over $2 \mathrm{Mw}$ up to $10 \mathrm{Gc} / \mathrm{s}$; bandwidths up to $3 \mathrm{Gc} / \mathrm{s}$ are indicated. Another source [Edson, 1960] indicates a current capability of about 50 Mw and a 1967 projected $125 \mathrm{Mw}$ level to $2 \mathrm{Gc} / \mathrm{s}$; the corresponding levels at $10 \mathrm{Gc} / \mathrm{s}$ are $10 \mathrm{Mw}$ and $50 \mathrm{Mw}$. 
From the standpoint of need, potential overall reliability, and wide frequency and dynamic ranges, the CRO seems still the most promising tool. Unfortunately, no progress has been reported beyond that of some years ago [Hergenrother and Rudenberg, 1953] when a 100-kv pulse CRO was described. The reader may be interested in frequency dependence of electric strength of various electrical insulation at frequencies to $100 \mathrm{Mc} / \mathrm{s}$ [Frisco, 1961]. Data are given for 31 different classes of materials; pulse applications at microwave frequencies are discussed and speculated upon. The results reported [Park and Cones, 1962] on spark gap flashover measurement may also be of interest. Linearly rising chopped impulses with peak voltages up to $300 \mathrm{kv}$ and times to sparkover from 0.03 to $50 \mu$ sec were measured employing a specially constructed divider and a cold cathode CRO. The results are intended for direct application to single impulses rather than to repetitious pulse problems. However, Gould [1959] has indicated the possibility of application of such results in the 10- to 100 -nsec range.

\subsubsection{Frequency, Bandwidth, and Time Intervals}

An improvement in resolving the line structure of microwave pulse spectra is claimed [Koontz, 1962] with a new spectrum analyzer employing coherent frequency conversion. Ability to inspect the "fine grain" structure of circuit outputs is important in order to detect and measure the noise and spurious modulation introduced by these circuits. A coherent converter translates a stable low frequency up to a microwave frequency which is used as the input into the circuit under test; the output spectrum is then reconverted down to the low frequency, using the same conversion chain; as a result, transfer oscillator instabilities are cancelled and the pulse spectrum, transferred to a low-frequency base, can be properly resolved by available filter design methods; the interline frequency spaces can then be conveniently studied. Such an analyzer was constructed with a $2 \mathrm{c} / \mathrm{s}(3-\mathrm{db})$ bandwidth filter. The most prominent causes of interline modulation in several UHF and $L$-band amplifiers tested were found to be power-line frequency modulation, mechanical vibration of cavity resonators, and instability of pulse repetition-frequency sources. An analytical discussion, block diagrams and experimental illustrations are included.

Time interval measurements requiring resolutions of the order of 500 psec were developed [Innes and Kerns, 1961]. The paper describes a pulsed light source used to stimulate scintillation from nuclear events. The light pulses were about 2 nsec long, had a rise time of the order of 0.1 to 0.6 nsec and 3000 $\mathrm{v}$ in amplitude into $50 \mathrm{ohms}$. The light pulse shape was measured by a sampling technique with a specially gated phototube; the grid of this tube was activated with pulse widths less than 0.7 nsec at the base. Nomograms to correct rise-time measurements obtained with CRO's having their own rise times commensurate with the unknown were published [Ransil, 1961]; these cover a range down to 1 nsec and lower. It was of interest to note that the commercially available high-speed scopes listed in that paper showed a range of 0.2 to 40 nsec rise times; one had a rise time of 350 and another 200 psec without resorting to the sampling technique. A circuit to automatically measure the rate of time displacement of pulses was described [Whatley, 1962]; it has been used to measure drift rates for changes of 50 to 500 nsec at repetition rates of 1000 to 2000 ppsec. The growing need of time resolutions of the order of 10 psec and better seems well illustrated in advanced carrier-pulse development work [Dietrich and Sharpless, 1961-62] where displays with 10 psec at clearly discernible variations per unit horizontal scale were used.

\subsubsection{Phase and Frequency Jitter (Instability of Parameters)}

An improvement of a technique used in previous years was developed [Sparks, 1962] to measure phase variations along narrow rf microwave pulses caused by tube parameter variations or general instabilities. A two-channel arrangement, balanced modulator, and homodyne detector are combined in a system to translate the phase information to a high intermediate frequency, e.g., $24 \mathrm{Mc} / \mathrm{s}$, tuned for a 10$\mathrm{Mc} / \mathrm{s}$ bandwidth. The output is observed on a CRO. For a pulse width of $1 \mu$ sec there were approximately four cycles of IF displayed. For no relative phase shift, the amplitudes of all four cycles were zero. In the presence of phase shift its magnitude was measured by adjusting a calibrated phase shifter in one of the channels and nulling the output amplitude as the phase was tracked across the width of the pulse. The repeatability of measurement on low and medium power 'TW'T's was less than $1 \mathrm{deg}$; an overall accuracy of $0.1 \mathrm{deg}$ was predicted if a precision phase shifter was used and further refinement of the system made. A technique and experimental setup to measure phase differences between individual pulses of a pulsed signal were described [Holman and Shields, 1961]. Phase differences up to $180 \mathrm{deg}$ were measured as a pulse to pulse rms deviation without a frequency reference from a signal source. A useful error analysis of a standard phase shifter was published [Schafer and Beatty, 1960]; it relates tuning errors of an adjustable-short-circuit three-arm standard phase shifter to detector output changes and treats errors of the order of 0.04 to 0.1 deg at 8 to $12 \mathrm{Gc} / \mathrm{s}$.

Time jitter is a difficulty associated particularly with gaseous discharge switches. Time jitters of the order of 2 nsec in 250 nsec and higher were encountered in switching kilovolt levels ['Theophanix, 1960]. Apparently no measurement difficulties were encountered in this case employing a CRO.

\subsubsection{Pulsed Current}

No progress was reported in measuring current pulses despite the apparent wide range requirements reaching peak values of 22,000 amp. A commercial clamp-on device was put on the market to measure 
current pulses over a range of 1 ma to $1 \mathrm{amp}$, and frequency range of about $25 \mathrm{c}$ to $20 \mathrm{Mc} / \mathrm{s}$, with claimed calibration stability of 1 percent.

\subsection{Sinusoidal CW Voltages and Currents}

The only published progress in these quantities during the time in question is an improvement in the accuracy of rf voltages of 1 to $200 \mathrm{v}$ at frequencies to $30 \mathrm{Mc} / \mathrm{s}$ from a previous 1 percent to 0.1 percent [Hermach and Williams, 1960]. Despite the evidence of the need for voltage measurements based, among other things, on spectral analysis requirements, no descriptions of sources of rf voltages to 5 or $10 \mathrm{Gc} / \mathrm{s}$ and no methods for their measurement were found in the usual technical publications. Commercial voltage generators to $10 \mathrm{Gc} / \mathrm{s}$ with microvolt to volt levels have been announced.

\section{References}

Carlson, R., S. Krakauer, K. Magleby, R. Monnier, V. Van Duzer, and R. Woodbury (1959), Sampling oscillography, IRE Wescon Conv. Record, Part 8, 44-51.

Dietrich, A. F. (May 1961), 8- and 11-Ge nanosecond carrier pulses produced by harmonic generation, Proc. IRE 49, Pt. 1, No. 5, 972-973.

Dietrich, A. F., and W. M. Sharpless (Feb. 1962), Carrier pulses at microwave and millimeter wave frequencies, 1962 Intern. Solid-State Circuits Conference Digest of Technical Papers, 1st ed., 78-79.

Euson, W. A. (Nov. 1960), Future trends in microwave beam tubes, Electron. Ind. 19, No. 11, 70-77.

Frisco, L. J. (Aug. 1961), Frequency dependence of electric strength, Electro-Technol. 68, No. 2, 110-116.

Gaddy, O. L. (Dec. 1960), A simple method of measuring fractional millimicrosecond pulse characteristics IRE Trans. Instr. I-9, No. 3, 326-332.

Gould, L. (Apr. 1959), Handbook on Breakdown of Air in Waveguide Systems (Microwave Associates, Inc., Burlington, Mass.).

Hergenrother, R. C., and H. G. Rudenberg (July 1953), A direct reading oscilloscope for $100 \mathrm{kv}$ pulses, Proc. IRE 41, No. 7, 896-901.
Hermach, F. L., and E. S. Williams (July 1960), Thermal voltage converters for accurate voltage measurements to 30 megacycles per second, Communications and Electronics (AIEE) 49, 200-206.

Holman, R. H., and R. B. Shields (Apr. 21, 1961), Measuring frequency stability of pulsed signals, Electronics 34, No. $16,61-65$.

Innes, T. G., and Q. A. Kerns (1961), A pulsed nanosecond light sourse, IRE Wescon Conv. Record, 5, Pt. 2, 23/2.

IRE Standards on Pulses (Nov. 1955), Methods of measurement of pulse quantities, Proc. IRE 43, No. 11, 1610-1616. (Electronic Industries Association Standard RS-242, EIA Engr. Dept., West 42d Street, New York 36, N.Y.)

Koontz, R. F.' (Nov. 1962), Fine grain spectrum analysis of pulsed microwave amplifiers, IRE Trans. MTT-10, No. 6, $440-455$.

Lang, O. B. (Sept. 8, 1961), Pulse voltage comparator measures height of positive or negative pulses, Electronics 34, No. 36, 70-71.

Lewis, I. A. D., and F. H. Wells (1959), Millimicrosecond Pulse Techniques, 2d ed. (Pergamon Press, bibliography of over 900 references; attention is called to table 61, 246.).

MacKenzie, R. P. (June 17, 1960), Novel design peak voltmeter, Electronics 33, No. 25, 57 .

Noel, D. R., and C. Susskind (Aug. 1961), An evaluation of kilomegacycle oscilloscopes, Electron. Ind. 20, No. 8, 92-98.

Park, J. H., and H. N. Cones (July-Sept. 1962), Spark gap flashover measurements for steeply rising voltage impulses, J. Res. NBS 66C, No. 3, 197-207.

Ransil, R. J. (Jan. 18, 1961), Nomograms to correct rise time measurements, Electron. Design 9, No. 2, 46-49.

Robertson, S. D. (Jan. 1949), A method of measuring phase at microwave frequencies, Bell Septe. Tech J. 28, No. 1, 99-103.

Schafer, G. E., and R. W. Beatty (Oct.-Dec. 1960), Error analysis of a standard microwave phase shifter, J. Res. NBS 64C, No. 4, 261-265.

Sparks, R. A. (Dec. 1962), A phase measuring system for short rf pulses, IRE Trans. Instr. I-11, No. 3.

Theophanis, G. A. (Apr. 1960), Millimicrosecond triggering of high voltage spark gaps, Rev. Sci. Instr. 31, No. 4, 427432.

Varian Associates, 611 Hansen Way, Palo Alto, California (1962 brochure), Microwave tubes and components for heavy radar, radar astronomy and linear accelerators, 2.

Whatley, W. W. (June 1962), Measuring pulse rate-ofdisplacement, Electron. Ind. 21, No. 6, G9-12.

Winnigstad, C. N. (Aug. 1961), Nanosecond pulse measurements, IRE Wescon Conv. Record, 5, Pt. 2, 23/1.

\section{Radio Noise Measurement Methods and Standards}

\section{W. W. Mumford}

\section{Bell Telephone Laboratories, Whippany, N.J.}

The full impact of the application and utilization of low-noise receivers such as the maser and the parametric amplifier was felt during the past two years. First, the tendency toward expressing the noise performance of a receiver in terms of a temperature rather than in terms of a noise figure gathered momentum. Second, the accurate evaluation of the noise performance of low-noise receivers demanded more precision in the calibration of noise generators. Third, the use of cold loads at liquid gas temperatures for noise measurements became practical. Some of these and other developments were highlighted at two important sessions devoted entirely to the subject.
The first of these sessions occurred during a week-long symposium sponsored jointly by Canada, the United Kingdom, and the United States on the Application of Low-Noise Receivers to Radar and Allied Equipment held at Lincoln Laboratory, MIT, Lexington, Mass., Oct. 24 through 28, 1960. The Proceedings were published in three volumes by Lincoln Laboratory, edited by Dr. James W. Meyer and Dr. Robert E. Rader. Dr. Hermann A. Haus was the chairman of the session which was devoted to Noise Measurements.

The second session was held at the 1961 PGMTT National Symposium sponsored by the Institute of Radio Engineers Professional Group on Microwave 
Theory and Techniques in Washington, D.C., May 17, 1961. This afternoon session was entitled "System and Receiver Noise Performance Clinic," and Dr. Hermann A. Haus was the Moderator. The Symposium Digest was published by the IRE.

The reason for the trend toward the use of an effective input noise temperature $T_{E}$ [Haus, 1960a; Adler, 1961], rather than noise figure, appears to be threefold [Meyer and Rader, 1960]. (1) There have been too many different definitions of noise figure published [Weber, 1960]. (2) In low-noise receivers it is easier to use $T_{E}$ than $F$, i.e., it is simpler to distinguish between $10^{\circ}$ and $15^{\circ}$ than it is to distinguish between 1.035 and 1.052 . (3) In multichannel receivers, $T_{E}$ and its measurements are definite, whereas $F$ depends upon the nature of the signals, i.e., whether the signal lies in one or more channels. There are those who think $F$ should be abandoned [Weber, 1960]. Although at least two new definitions of $T_{E}$ [Haus, 1960b; Adler, 1961] have been proposed recently, the definition which describes a directly measurable and unambiguous quantity may be the one which survives the rigors of general acceptance. This one [Adler, 1961] is convenient to use to express the total output noise power thus:

$$
\begin{gathered}
N_{0}=G_{1} k B_{1}\left(T_{g 1}+T_{e}\right)+G_{2} k B_{2}\left(T_{g 2}+T_{e}\right)+\ldots \\
\ldots+G_{n} k B_{n}\left(T_{g n}+T_{e}\right)
\end{gathered}
$$

where $G_{n} B_{n}$ and $T_{g n}$ represent the gains, bandwidths and generator noise temperatures at the $n$th response or channel of the receiver, and $T_{E}$ is readily measurable with a hot and cold load, thus:

$$
T_{e}=\frac{T_{g \text { (hot })}-Y T_{g(\text { cold })} .}{Y-1} .
$$

More precise calibration of noise sources has been achieved and maintained as a calibration service by the National Bureau of Standards at $X$-band using a heated waveguide load as a standard for comparison in a radiometer setup [Estine, 1960; Wells, 1962]. In their latest version the uncertainties give a total error of only $0.07 \mathrm{db}$ in the excess noise ratio of a suitable unknown noise source. Preliminary results [Estine, 1960] on the Bendix TD-11 had indicated an excess noise ratio of the tube in mount of $15.9 \mathrm{db}$. Subsequent improvements in the technique led to results [Wells, 1962] more nearly in agreement with the calculated electron temperature, around $10,900^{\circ}$, which with the tube in mount results in an excess noise ratio of $15.55 \mathrm{db}$ [Lee, 1962]. The agreement between calculated electron temperature and noise temperature was somewhat closer than that observed by Bekefi, and Brown [1961], whose measurements on helium, neon, and hydrogen indicated a noise temperature somewhat less than the calculated electron temperature.

Using the NBS calibration service, Lee and Olson at Bendix obtained calibrations on several $X$-band tubes and then, using these as standards, calibrated a number of their other tubes in different frequency ranges and published the results [Lee, 1962]. general, the agreement between calculated electron temperature and noise temperature was good.

Associated with the demand for greater precision in measuring low noise receivers, cold loads were employed [Grimm, 1960; Macpherson, 1962; De Grasse and Scovil, 1960; De Grasse, Ohm, Hogg, and Scovil, 1959a; Stelzried, 1961]. Here the physical temperature of the loads could be measured quite precisely and used to determine the noise figure. The ensuing calibration of argon gas discharge noise sources often led to values of excess noise temperatures which were higher than those quoted in the past by the manufacturers and indeed were closer to the values obtained from electron temperature calculations and subsequent calibrations [Ohm, 1961; De Grasse, Ohm, Hogg, and Scovil, 1959b].

Automatic noise figure meters were developed, in which the noise figure is read directly on a meter [Kuhn and Negrete, 1961; Bruck, 1960; Chenette and Van Der Ziel, 1962]. Pulsed operation presented some problems.

The pitfalls of noise figure measurement were enumerated in an amusing article on noisemanship by J. C. Green [1961].

A low-frequency noise source using two ganged potentiometers at different temperatures was devised and described by A. C. Macpherson [1962].

Theoretical studies of noise and its measurement were presented. The uncertainty principle was applied to prove that a finite minimum effective input noise temperature existed; a linear noiseless amplifier is impossible [Heffner, 1962; Siegman, 1961]. The effect of mismatch of the source impedance was derived in terms of measurable quantities [Haus, 1960b]. A résumé of various definitions of noise factor and other noise performance rating schemes was presented [Enslow, 1961]. Definition of temperature sensitivity including negative conductance devices was proposed [Fisher, 1962]. Standards on methods of measuring noise were published by the IRE [Haus, 1960a; Esperson, 1962].

\section{References}

Adler, R., R. S. Engelbrecht, H. A. Haus, M. T. Lebenbaum, and W. W. Mumford (May 1961), Elementary considerations of noise performance, Digest of Tech. Papers, IRE PGMTT National Symposium, Washington, D.C. (IRE, New York).

Bekefi, G., and S. C. Brown (Jan. 1961), Microwave measurements of the radiation temperature of plasmas, J. Appl. Phys. 32, 25-30.

Bruck, G. (July 1960), Direct reading noise figure measuring device, Proc. IRE 48, 1342.

Chenette, E. R., and A. Van Der Ziel (Mar. 1962), Accurate noise measurements on transistors, IRE Trans. Electron Devices 9, 123.

De Grasse, R. W., D. C. Hogg, E. A. Ohm, and H. E. D. Scovil (1959a), Ultra-low-noise antenna and receiver combination for satellite or space communication, Proc. Natl. Electron. Conf. 15, 370-379.

De Grasse, R. W., D. C. Hogg, E. A. Ohm, and H. E. D Scovil (Dec. 1959b), Ultra-low-noise measurements using a horn reflector antenna and a travelling wave maser, J. Appl. Phys. 30, 2013.

De Grasse, R. W., and H. E. D. Scovil (Feb. 1960), Noise temperature measurement on a travelling wave maser preamplifier, J. Appl. Phys. 31, 443-444. 
Enslow, P. H., Jr. (July 1961), Noise figures, noise temperatures, and system sensitivity, Tech. Rept. No. 516-2, AD-265 552 Div. 8, Contract DA-36-39-sc-78296, Stanford Electronics Labs, Stanford Univ.

Esperson, G. A., et al. (1962), IRE standards on electron tubes, Methods of Testing 1962-62 IRE, 7.51 (IRE, New York).

Estine, A. J., C. L. Trembath, J. S. Wells, and W. C. Daywitt (Sept. 1960), Absolute measurement of temperatures of microwave noise sources, IRE Trans. Instr. 9, No. 2, 209213.

Fisher, S. T. (Feb. 1962) A completely consistent definition of temperature sensitivity including negative conductance devices, Proc. IRE 50, 204.

Greene, J. C. (July 1961), Noisemanship-The art of measuring noise figures nearly independent of device performance, Proc. IRE 49, 1223.

Grimm, H. H. (Feb. 1960), Noise temperature in a radar system, Proc. IRE 48, 246.

Haus, H. A., et al. (Jan. 1960a), IRE standards on methods of measuring noise in linear twoports, 1959-59 IRE 20 S1, Proc. IRE 48, 60-68.

Haus, H. A., et al. (Jan. 1960b), Representation of noise in linear twoports, Proc. IRE 48, 69-74.

Heffner, H. (July 1962), The fundamental noise limit of linear amplifier, Proc. IRE 50, 1604-1607.

Kuhn, N. J., and M. R. Negrete (Mar. 1961), Gas discharge noise sources in pulsed operation, IRE Intern. Conv. Rec., Pt. 3, Electron Devices and Microwave Tech. Theory, 166.
Lee, R. A., and K. W. Olson (May 1962), Absolute values of excess noise ratio traceable to the Bureau of Standards, Bendix Red Bank Eng. Data Release, Issue No. 40 (Bendix Aviation Corp., Eatontown, N. J.).

Macpherson, A. C. (Mar. 1962), Low frequency standard noise source, Rev. Sci. Instr. 33, 386-387.

Meyer, J. W., and R. E. Rader (Nov. 1960), ed., Discussion, Noise figure, noise temperature and noise factor, Proc. Symposium on the Application of Low Noise Receivers to Radar and Allied Equipment III, 349-362 (Lincoln Lab., MIT, Lexington, Mass.).

Ohm, E. A. (July 1961), Project Echo receiving system, Bell Systems Tech. J. 40, 1065-1094.

Siegman, A. E. (Sept. 1961), Thermal noise in microwave systems, Tech. Rept. No. 157-3, AD-262 413 Div. 8, Contract AF 33(616)-7944, Stanford Electronics Labs., Stanford Univ.

Stelzried, C. T. (July 1961), A liquid-helium-cooled coaxial termination, Proc. IRE 49, 1224.

Weber, J. (Nov. 1960), Some aspects of noise measurement, Proc. Symposium on the Application of Low Noise Receivers to Radar and Allied Equipment II, ed. J. W. Mever and R. E. Rader, 57-75 (Lincoln Lab., MIT, Lexington, Mass.).

Wells, J. S., W. C. Daywith, and C. K. S. Miller (Mar. 1962), Measurement of effective temperatures of microwave noise sources, IRE Internat. Conv. Rec., Pt. 3, Electron Devices and Microwave Theory Tech., 221-238.

\title{
6. Measurements at Millimeter and Submillimeter Wavelengths
}

\author{
R. G. Fellers \\ University of South Carolina, Columbia S.C.
}

\begin{abstract}
The development of measurement techniques in the millimeter and submillimeter range has been accelerated by improvements in sources and the development of transmission systems including conventional dominant mode waveguide, $\mathrm{TE}_{01}$ mode circular waveguide, oversized rectangular waveguide, and free-space transmission systems with and without beam-guiding techniques.
\end{abstract}

\section{Devices and Techniques in Dominant Mode Waveguide}

The design of most standard components such as slotted lines, wavemeters, and attenuators has been extended to the 1.5 to 2 millimeter range. They are all characterized by close tolerances and precision fabrication methods. New developments include a standing-wave indicator using a fixed detector and a phase shifter and an impedance meter which measures the modulus and argument of the reflection coefficient by using the principle of the rotary attenuator [Bertan, 1960].

A $Y$ circulator has been constructed with good performance at $140 \mathrm{Gc} / \mathrm{s}$ and a ferrite phase-shifter with a full $360^{\circ}$ phase shift and a low loss (less than $0.45 \mathrm{db}$ ) has been developed for use at $35 \mathrm{Gc} / \mathrm{s}$ [Thaxter and Heller, 1960; McCarter and Landry, 1961].

A yttrium-iron-garnet resonator with $Q$ values of several thousand has been developed for use at 35 and $70 \mathrm{Gc} / \mathrm{s}$ [Douthett and Kaufman, 1961].
Microwave type bolometers have been developed for use in the 0.25 to $2 \mathrm{~mm}$ range. They employ a horn-fed rectangular waveguide followed by a waveguide to coaxial line transition in which the bolometer is mounted. Sensitivities of the order of $10^{-11} \mathrm{w}$ have been obtained [Byrne and Coor, 1963].

A ferrite isolator and variable attenuator has been designed for use at 50 to $60 \mathrm{Gc} / \mathrm{s}$. As an attenuator the minimum loss is $1 \mathrm{db}$ and the maximum loss 30 db over the band [Barnes, 1961].

A relatively conventional attenuator for $60 \mathrm{Gc} / \mathrm{s}$ use has been developed with a VSWR less than 1.1, a minimum attenuation of $0.2 \mathrm{db}$ and a $10-\mathrm{w}$ power dissipation [Wolfert, 1963].

\subsection{Devices and Techniques in Free-Space Transmission}

The development of free-space transmission techniques has led to the development of the free-space equivalent of many devices such as attenuators, hybrids, directional couplers, wavemeters, and standing wave indicators [Fellers, 1962]. 
Fabry-Perot interferometers have been developed with accuracies of 0.04 percent and $Q$ values of 100,000 [Culshaw, 1960]. Recent developments of resonators have resulted in $Q$ values of 300,000 at 0.1 mm [Culshaw, 1961; Culshaw, 1962].

Further developments of the Michelson Interferometer have produced a device using Fresnel zone plates with resulting high accuracy. This device has been used to measure dielectric constant and loss tangent at 140 and $210 \mathrm{Gc} / \mathrm{s}$ [Sobel, Wentworth, and Wiltse, 1961].

An arrangement of two dielectric prisms with adjustable spacing permits the adjustment of the fraction of energy which is passed through the prisms. This arrangement has found application as a halfsilvered mirror, a hybrid junction, an adjustable attenuator, and an adjustable bidirectional coupler. The device is capable of theoretical calibration and has many measurement applications in interferometers, reflectometers, and the like [Fellers, 1962; Raker and Valenzuela, 1962].

An application of "a quasi-optical directional coupler (dielectric sheet), to detector impedance measurement has produced usable results at $1 \mathrm{~mm}$ [Miller, Szente, and Mallory, 1963].

\subsection{Devices and Techniques in Oversized Waveguide}

The use of oversized waveguide for reduced attenuation has resulted in the development of a number of measuring devices.

The prism arrangement used in free space has been employed in oversized rectangular waveguide to produce a directional coupler, variable attenuator, and a variable phase-shifter. Coupling ratios of 0 to 30 $\mathrm{db}$ can be obtained at $300 \mathrm{Gc} / \mathrm{s}$, but the insertion loss is 2 to $3 \mathrm{db}$. Variable attenuators have been constructed with attenuation of 1 to $30 \mathrm{db}$. A variable phase-shifter has been produced by the use of variable short circuits in two of the ports of the directional coupler [Taub, Hindin, Kinckelmann, and Wright, 1963; Hindin and Taub, 1962].

Broad-band directional couplers in multimode waveguide have been developed for use in the 35-580 $\mathrm{Gc} / \mathrm{s}$ band with low insertion loss and good directivity [Marcatili and Ring, 1962].

Standing-wave indicators using cylindrical sleeve sections have been constructed in $\mathrm{TE}_{01}$ circular guide. In the same waveguide a high-power attenuator is being developed by permitting the energy to leak out from the guide into a lossy medium [Simmons, 1963].

A channel dropping filter operating at $56 \mathrm{Gc} / \mathrm{s}$ converts $\mathrm{TE}_{01}$ mode energy in circular guide to $\mathrm{TE}_{10}$ mode energy in rectangular guide. Bandwidth is $185 \mathrm{Mc} / \mathrm{s}$ and insertion loss is $1.4 \mathrm{db}$ [Marcatili, 1961].

\subsection{Miscellaneous Devices and Techniques}

A continuously tunable radiometer which does not require a coherent source is useful for making transmission measurements in the 50 to $90 \mathrm{Gc} / \mathrm{s}$ band. The instrument utilizes a continuously tunable elec- tromechanical band-pass filter and has demonstrated high sensitivity [Long and Butterworth, 1963].

A perturbation method of measuring millimeterwave fields has been devised. It utilizes a small metallic reflector which is rotated in the field and which can be scanned through the field. Signal reflected from the rotating reflector is mixed with a reference signal for measurement [Wolfert and Schiller, 1963].

A technique for measurement of dielectric and magnetic properties in the 3 to $100 \mathrm{Gc} / \mathrm{s}$ range has an accuracy of \pm 0.1 percent. The measuring structure is made up of a dielectric rod between two parallel conducting plates. Dielectric and magnetic properties are computed from resonant frequencies, dimensions, and unloaded Q [Hakki and Coleman, 1960].

\section{References}

Barnes, C. E. (Nov. 1961), Broad band isolators and variable attenuators for millimeter wavelengths, IRE Trans. Microwave Theory Tech. 9, 519-523.

Bertan, L. L. (Sept. 1960), Consideration in the design of two millimeter wave components, Proc. Fourth Annual Joint Military-Industrial Electronic Test Equipment Symposium, 113-130.

Byrne, J. F., and C. F. Cook (Jan. 1963), Microwave type bolometer for submillimeter wave measurements, Digest of Millimeter and Submillimeter Conference, Orlando, Fla.

Culshaw, W. (Mar. 1960), High resolution millimeter wave interferometer, IRE Trans. Microwave Theory Tech. 9, $182-189$.

Culshaw, W. (Mar. 1961), Resonators for millimeter and submillimeter wavelengths, IRE Trans. Microwave Theory Tech. 9, 135-144.

Culshaw, W. (Sept. 1962), Further consideration on FabryPerot type resonators, IRE Trans. Microwave Theory Tech. 10, 331-339.

Douthett, D., and I. Kaufman (May 1961), The unloaded $Q$ of a YIG resonator from $X$-band to 4 millimeters, IRE Trans. Microwave Theory Tech. 9, 261-262.

Fellers, R. G. (May 1962), Non-waveguide methods of millimeter wave transmission, Microwave J. 5, 80-86.

Hakki, B. W., and P. D. Coleman (July 1960), A dielectric resonator method of measuring inductive capacities in the millimeter range, IRE Trans. Microwave Theory Tech. 8, $402-410$.

Hindin, H. J., and J. J. Taub (Sept. 1962), Oversize wave guide directional doupler, IRE Trans. Microwave Theory Tech. 10, 392-393.

Long, M. W., and J. C. Butterworth (Jan. 1963), A new type microwave radiometer, Digest of Millimeter and Submillimeter Conference, Orlando, Fla., 37-38.

McCarter, R. S., and E. F. Landry (May 1961), Ka-band ferrite phase shifter, IRE Trans. Microwave Theory Tech. $\mathbf{9}, 271$.

Marcatili, E. A. J. (Mar. 1961), A channel dropping filter in the millimeter region using circular electric modes, IRF Trans. Microwave Theory Tech. 9, 176-182.

Marcatili, E. A., and D. H. Ring (July 1962), Broad band directional couplers, IRE Trans. Microwave Theory Tech. 10, $251-257$.

Miller, R. H., P. A. Szente, and K. B. Mallory (Jan. 1963), A measurement of detector impedance at millimeter and submillimeter wavelengths, Digest of Millimeter and Submillimeter Conference, Orlando, Fla., 40-41.

Raker, H. D., and G. R. Valenzuela (Sept. 1962), A double prism attenuator for millimeter waves, IRE Trans. Microwave Theory Tech. 10,392-393.

Simmons, A. J. (Jan. 1963), TE $\mathrm{T}_{01}$ components in the 3 millimeter region, Digest of Millimeter and Submillimeter Conference, Orlando, Fla., 17-18. 
Sobel, F., F. L. Wentworth, and J. C. Wiltse (Nov. 1961), Quasi-optical surface waveguide and other components for the 100 to $300 \mathrm{Gc}$ region, IRE Trans. Microwave Theory Tech. 9, 512-518.

Taub, J. J., H. J. Hindin, O. Kinckelmann, and M. L. Wright (Jan. 1963), Submillimeter components using oversize quasi-optical waveguide, Digest of Millimeter and Submillimeter Conference, Orlando, Fla., 12-13.
Thaxter, J. B., and G. S. Heller (Jan. 1960), Circulators at 70 and 140 KMC, Proc. IRE 48, 110-111.

Wolfert, P. (Jan. 1963), Design of some new $V$-band components, Digest of Millimeter and Submillimeter Conference, Orlando, Fla., 25.

Wolfert, P., and T. Schiller (Jan. 1963), A relative amplitude and phase plotter for millimeter antenna design, Digest of Millimeter and Submillimeter Conference, Orlando, Fla., 39 .

\title{
7. Precise Measurements of Distance and of the Velocity of Light Using Lasers
}

\author{
Peter L. Bender \\ Joint Institute for Laboratory Astrophysics, Boulder, Colo.
}

One of the major accomplishments of the past 3 years in the area of radio science has been the development of coherent sources of light called optical masers or lasers. These devices have greatly extended the range of frequencies over which the techniques developed in the normal radio and microwave ranges can be applied. The most immediate applications appear to be in the areas of basic science, communications, and precise distance measurements.

A number of types of lasers is now available. These include pulsed and continuous optically pumped solid-state lasers, $Q$-switched solid-state lasers, continuous rf discharge and optically pumped gas lasers, and electron injection semiconductor lasers. The type which appear to be most applicable to precise distance measurement are the $Q$-switched solid-state laser and the gas laser.

In the Q-switched laser [Hellwarth, 1961; McClung and Hellwarth, 1962] a large inverted population difference between two energy levels of a crystal is produced by optical pumping while the $Q$ of the optical cavity is low. The $Q$ is then rapidly switched to a high value, usually by opening a Kerr cell shutter in the optical path or rotating a 90-degree prism so that its plane of retroreflection becomes perpendiclar to a plane reflector forming the other end of the optical cavity. This gives a rapid buildup of power in the cavity and a quick dumping of the inverted population in the crystal. Output pulses as short as 10 nsec with a peak power output of over $50 \mathrm{Mw}$ and a narrow output beam width have been obtained [Marshall, Roberts, and Wuerker, 1962]. This type of device appears superior to microwave methods for radar-type measurements of long distances under some circumstances.

Gas lasers [Javen, 1959; Faust, McFarlane, Patel, and Garrett, 1962], on the other hand, have much lower output power but run continuously. Their demonstrated spectral purity of a few parts in $10^{13}$ [Jaseja, Javan, Murray, and Townes, 1962], and independent resettability of about 1 part in $10^{9}$ [Javen] make possible extremely accurate measurements over quite long vacuum paths. With such devices the limitation on path lengths over which interference measurements can be made appears to lie mainly in the problem of finding the whole fringe number or in path stability rather than in the coherence length, as was previously the case. Gas laser output wavelengths of $0.63 \mu$ [White and Ridgen, 1962] to $12.9 \mu$ [Faust, McFarlane, Patel, and Garrett, 1962] have already been obtained. These wavelengths can be supplemented by using beat wavelengths between two laser modes corresponding to different optical transitions as the basic unit of measurement. For example, if the 1.1143- $\mu$ [McFarlane, Patel, Bennett, and Faust, 1962] and 1.1177- $\mu$ [Javan, Bennett, and Herriott, 1961] transitions in neon are employed, the best wavelength will be $0.32 \mathrm{~mm}$. Still longer beat wavelengths can be obtained by using two different axial modes for the same optical transition or by using a microwave modulator [Bloembergen, Pershan, and Wilcox, 1960; Pershan and Bloembergen, 1961] to modulate the light output from either a laser or a conventional light source. Quite short beat wavelengths may be obtainable on a pulsed basis with a microwave modulator operated with a high modulation index, but for continuous operation the index which can be used appears to be limited by heat dissipation in the modulator crystal.

Paths of up to $864 \mathrm{~m}$ have previously been measured in terms of shorter paths by means of white light fringes with multiple reflections [Fabry and Buisson, 1919; Honkasalo, 1960]. With lasers, measurements over quite long paths can also be done by using automatic fringe counters or by using several different wavelengths and beat wavelengths calibrated with respect to each other over shorter paths in order to obtain the whole fringe number. Probably the simplest method is to use white light fringes to set the long path to an integral multiple of a shorter path for which the whole number of laser fringes is known, and then to measure the long path to the desired fraction of a fringe with a laser source. With such procedures the accuracy of measuring long and stable vacuum paths will probably be limited 
mainly by the uncertainty in the length standards.

For a precise measurement of the velocity of the light $c$ at optical wavelengths, a common method is to use two optical frequencies $\nu_{1}$ and $\nu_{2}$ with a difference $\Delta \nu$ known in frequency units. The number of beat wavelengths over a distance $L$ known in length units is measured. If $n_{1}$ and $n_{2}$ are the number of fringes for the two wavelengths, then $\nu_{2}=n_{2} \cdot \frac{c}{2 L}$, $\nu_{1}=n_{1} \cdot \frac{c}{2 L}, \Delta \nu=\left(n_{2}-n_{1}\right) \cdot \frac{c}{2 L}$, and $c=2 L \cdot \frac{\Delta \nu}{\left(n_{2}-n_{1}\right)}$. For a given path length $L$, it is normally advantageous to use as high a difference frequency $\Delta \nu$ as can be determined accurately so that $n_{2}-n_{1}$ will be large. Making $L$ large is also desirable in order to make $n_{2}-n_{1}$ large, as long as the additional path length does not increase the uncertainty in terms of fractions of a fringe to which $\left(n_{2}-n_{1}\right)$ can be measured.

At the National Bureau of Standards an attempt is planned to measure the beat frequency of about $831 \mathrm{Gc} / \mathrm{s}$ between the two neon laser lines at 1.1143 and $1.1177 \mu$ which were mentioned earlier. The method, which was suggested by Z. L. Bay, is to intensity modulate the beam of a special cathode ray tube at the $831 \mathrm{Gc} / \mathrm{s}$ beat frequency by illuminating the photo-cathode spot with both laser lines. If the frequency applied to the horizontal deflection plates is near a subharmonic of the beat frequency, a slowly running intensity modulated pattern will be produced on the face of the tube. For a roughly 10 $\mathrm{Gc} / \mathrm{s}$ deflection frequency and fairly rapid initial acceleration of the beam, the percentage modulation of the pattern should be adequate for measurement of the running frequency and thereby of the beat frequency [Statz, Paananen, and Koster, 1962]. If this attempt is successful, the method is intended for use in a velocity of light measurement over a suitable path length.

\section{References}

Bay, Z. L., and H. S. Boyne, Private communication.

Bloembergen, N., P. S. Pershan, and L. R. Wilcox (1960), Microwave modulation of light in paramagnetic crystals, Phys. Rev. 120, 2014.

Fabry, C., and H. Buisson (1919), Indications techniques sur les étalons interferentiels a lames Argentees, J. Physique 9, 189 .

Faust, W. L., R. A. McFarlane, C. K. N. Patel, and C. G. B. Garrett (1962), Gas maser spectroscopy in the infrared, Appl. Phys. Ltrs. 1, 85.

Hellwarth, R. W. (1961), Control of fluorescent pulsations, Advances in Quantum Electronics, p. 334, ed. J. R. Singer (Columbia Univ. Press, New York and London).

Honkasalo, T. (1960), Measurement of standards base line with the Väisälä light-interference comparator, J. Geophys. Res. 65, 457.

Jaseja, T. S., A. Javan, J. Murray, and C. H. Townes (1962), Stability and resettability of $\mathrm{He}-\mathrm{Ne}$ masers, Bull. Amer. Phys. Soc. $\boldsymbol{7}, 553$.

Javan, A., Private communication.

Javan, A. (1959), Possibility of production of negative temperature in gas discharges, Phys. Rev. Ltrs. 3, 87.

Janvan, A., W. R. Bennett, and D. R. Heriott (1961), Population inversion and continuous optical maser oscillation in a gas discharge containing a He-Ne mixture, Phys. Rev. Ltrs. 6, 106 .
McClung, F. J., and R. W. Hellwarth (1962), Giant optica pulsations from ruby, J. Appl. Phys. 33, 828.

McFarlane, R. A., C. K. N. Patel, W. R. Bennett, and W. L Faust (1962), New helium-neon optical maser transitions, Proc. IRE 50, 2111.

Marshall, F. R., D. L. Roberts, and R. F. Wuerker (1962), Energy storage and radiation emission from Kerr-cellcontrolled lasers, Bull. Amer. Phys. Soc. \%, 445.

Pershan, P. S., and N. Bloembergen (1961), Microwave modulation of light, Advances in Quantum Electronics, p 187, ed. J. R. Singer (Columbia Univ. Press, New York and London).

Statz, H., R. Paananen, and G. F. Koster (1962), Zeeman effect in gaseous helium-neon optical maser, J. Appl. Phys. 33, 2319.

White, A. D., and J. D. Rigden (1962), Continuous gas maser operation in the visible, Proc. IRE 50, 1697.

\section{Additional References}

Bennett, W. R. (1962), Hole burning effects in a He-Ne optical maser, Phys. Rev. 126, 580.

Bennett, W. R., W. L. Faust, R. A. McFarlane, and C. K. N. Patel (1962), Dissociative excitation transfer and optical maser oscillation in $\mathrm{Ne}-\mathrm{O}_{2}$ and $\mathrm{Ar}-\mathrm{O}_{2} \mathrm{rf}$ discharges, Phys. Rev. Ltrs. 8, 470.

Bennett, W. R., and P. J. Kindlmann (1962), Magnetostrictively tuned optical maser, Rev. Sci. Instr. 33, 601.

Fabry, C. (1923), Les Applications des Interférences Luminenses, p. 82.

Froome, K. D., and R. H. Bradsell (1961), Distance measurement by means of a light ray modulated at a microwave frequency, J. Sci. Instr. 38, 458.

Herriott, D. R. (1962), Optical properties of a continuous helium-neon optical maser, J. Opt. Soc. Am. 52, 31.

Javan, A. (1960), Possibility of obtaining negative temperature in atoms by electron impact, Quantum Electronics, p. 564, ed. C. H. Townes, (Columbia Univ. Press, New York and London).

Javan, A. (1961), Optical maser oseillations in a gaseous discharge, Advances in Quantum Electronics, p. 18, ed. J. R. Singer (Columbia Univ. Press, New York and London); W. R. Bennett, ibid., p. 28; D. R. Herriott, ibid., p. 44.

Javan, A., E. A. Ballik, and W. L. Bond (1962), Frequency characteristics of a continuous-wave He-Ne optical maser, J. Opt. Soc. Am. 52, 96.

Kaminow, I. P. (1961), Microwave modulation of the electrooptic effect in $\mathrm{KH}_{2} \mathrm{PO}_{4}$, Phys. Rev. Ltrs. 6, 528.

Kogelnik, H., and C. K. N. Patel (1962), Mode suppression and single frequency operation in gaseous optical masers, Proc. IRE 50, 2365.

Patel, C. K. N. (1962), Optical power output in He-Ne and pure Ne maser, J. Appl. Phys. 33, 3194.

Patel, C. K. N., W. R. Bennett, W. L. Faust, and R. A. McFarlane (1962), Infrared spectroscopy using stimulated emission techniques, Phys. Rev. Ltrs. 9, 102.

Patel, C. K. N., W. L. Faust, and R. A. MeFarlane (1962), High gain gaseous (Xe-He) optical masers, Appl. Phys. Ltrs. 1, 84 .

Rabinowitz, P., S. Jacobs, and G. Gould (1962), Continuous optically pumped Cs laser, Appl. Opt. 1, 513.

Rigden, J. D., and A. D. White (1962), Simultaneous gas maser action in the visible and infrared, Proc. IRE 50, 2366.

Rigrod, W. W., H. Kogelnik, D. J. Brandaccio, and D. R. Herriott (1962), Gaseous optical maser with external concave mirrors, J. Appl. Phys. 33, 743.

Sears, J. E., and H. Barrell (1933), A new apparatus for determining the relationship between wavelengths of light and the fundamental standards of length, Phil. Trans. Roy. Soc. (London) Ser. A, 231, 75.

Tang, C. L., and H. Statz (1962), Nonlinear effects in the resonant absorption of several oscillating fields by a gas, Phys. Rev. 128, 1013.

Väisälä, Y. (1923), Die Anwendung der Lichtinterferenz zu Längenmessungen auf grosseren Distanzen, Veroffentl. Finn. Geod. Inst. 2, Helsinki. 


\title{
Appendix: Measurements Standards and Calibration Laboratories in the United States
}

\author{
C. E. White
}

\section{AVCO Corporation, Wilmington, Mass.}

\section{Part 1}

A measurements capability survey, conducted for a group of 181 laboratories in the United States, provided the basic background for the compilation of this report. From this survey, a number of measurements laboratories were determined to have accuracy capabilities better than average in one or more fields of microwave measurements. These laboratories have been listed below, with coded notations to indicate the specialized capabilities. The coded notations appear as a separate listing.

\begin{tabular}{|c|c|c|}
\hline Laboratory & Location & Capabilities \\
\hline AVCO-Electronics & Cincinnati, Ohio_. & $\mathrm{F} 1, \mathrm{~F} 2, \mathrm{P} 1, \mathrm{P} 2, \mathrm{~V} 1, \mathrm{Z} 1$, \\
\hline AVCO R.A.D & Wilmington, Mass & $\begin{array}{l}\mathrm{F} 1, \mathrm{~A} 1, \mathrm{~A} 2, \mathrm{~A} 3,(\mathrm{~A} 4 \text { to } \\
\mathrm{Gc} / \mathrm{s}), \mathrm{P} 1, \mathrm{Z} 3\end{array}$ \\
\hline $\begin{array}{l}\text { Ballantine Lab. Inc } \\
\text { Ball Rros. Research Corp } \\
\text { Bell Telephone Lab }\end{array}$ & $\begin{array}{l}\text { Boonton, N.J } \\
\text { Boulder, Colo-...- } \\
\text { Allentown, Pa_..... }\end{array}$ & $\begin{array}{l}18 \mathrm{Gc} / \mathrm{s}) \\
\mathrm{V} 1, \mathrm{~V} 2 \\
\mathrm{~F} 1, \mathrm{~F} 2, \mathrm{~A} 1, \mathrm{P} 1, \mathrm{~V} 1, \mathrm{Z} 1 \\
\mathrm{~F} 1, \mathrm{~F} 2\end{array}$ \\
\hline Bell Telephone Lab_. & Murray Hill, N.J & $\begin{array}{l}\left.\mathrm{F} 1, \mathrm{P} 1, \mathrm{P} 2, \mathrm{P} 3,{ }^{(\mathrm{P}} 4\right), \\
\mathrm{Z} 1, \mathrm{Z} 2, \mathrm{Z} 3,(\mathrm{Z} 4)(60\end{array}$ \\
\hline $\begin{array}{l}\text { Bendix-Kansas City Div } \\
\text { Bendix-Pacific Div }\end{array}$ & $\begin{array}{l}\text { Kansas City, Mo } \\
\text { N. Hollywood, Calif }\end{array}$ & $\begin{array}{l}\mathrm{F} 1, \mathrm{P} 2, \mathrm{Z} 2 \\
\mathrm{~F} 1, \mathrm{~F} 2, \mathrm{~F} 3,(\mathrm{~F} 4), \mathrm{Z} 1, \\
\mathrm{Z} 2, \mathrm{Z} 3,(\mathrm{Z} 4) \text { (to } 18\end{array}$ \\
\hline Bendix-Radio Div & Baltimore, Md... & $\begin{array}{l}\mathrm{Gc} / \mathrm{s}) \\
\mathrm{F} 1, \mathrm{~V} 1, \mathrm{Z} 1, \mathrm{Z} 2, \mathrm{Z} 3,(\mathrm{Z} 4)\end{array}$ \\
\hline Boeing Co. (Aerospace Div). & Seattle, Wash_. & $\begin{array}{l}\mathrm{F} 1, \mathrm{~A} 1, \mathrm{~A} 2, \mathrm{~A} 3, \mathrm{P} 1, \mathrm{P} 2, \\
\mathrm{P} 3, \mathrm{Z} 1, \mathrm{Z} 2\end{array}$ \\
\hline $\begin{array}{l}\text { Boonton Radio Co } \\
\text { Borg-Warner Research }\end{array}$ & $\begin{array}{l}\text { Rockaway, N.J. } \\
\text { Des Plaines. II- }\end{array}$ & $\begin{array}{l}\text { Q1, Q2 } \\
\text { P1, V1 }\end{array}$ \\
\hline Collins R & Cedar Rapids, Iowa & F1, P1, P2, V1, Z1, Z2, \\
\hline Cook Electric Co.. & Morton Grove, Ill_. & (V1 to $4 \mathrm{Mc} / \mathrm{s}$ ), Z1, Z2, \\
\hline Douglas Aircraft Co & Santa Monica, Calif & $\begin{array}{l}\mathrm{F} 1, \mathrm{~F} 2, \mathrm{~F} 3,(\mathrm{~F} 4), \mathrm{A} 2, \\
\mathrm{~A} 3,(\mathrm{~A} 4), \mathrm{Z} 3, \mathrm{~N} 3 \text { (to } \\
18 \mathrm{Gc} / \mathrm{s})\end{array}$ \\
\hline Empire Devices, Inc... & Amsterdam, N.Y & $\mathrm{N} 1, \mathrm{~N} 2, \mathrm{~N} 3$ (N4 to 40 \\
\hline Ewen Knight Corp & East Natick, Mass. & $\mathrm{N}_{2}$, N3, (N4) (to 75 \\
\hline $\begin{array}{l}\text { Frequency Engrg. Lab } \\
\text { Gen. Dynamics-Astronautics } \\
\text { Gen. Dynamies-Convair }\end{array}$ & $\begin{array}{l}\text { Asbury Park, N.J. } \\
\text { San Diego, Calif } \\
\text { San Diego, Calif... }\end{array}$ & $\begin{array}{l}\mathrm{F} 3(\mathrm{~F} 4 \text { to } 40 \mathrm{Gc} / \mathrm{s}) \\
\text { F1, F2 } \\
\text { P1, P2, P3, (P4), V1, } \\
\text { V2, Z1, Z2, Z3, (Z4) } \\
\text { (to } 40 \mathrm{Gc} / \mathrm{s})\end{array}$ \\
\hline $\begin{array}{l}\text { General Electric Co } \\
\text { General Radio Co } \\
\text { Hewlett-Packard Co }\end{array}$ & $\begin{array}{l}\text { Philadelphia, Pa } \\
\text { West Concord, Mass } \\
\text { Palo Alto, Calif }\end{array}$ & $\begin{array}{l}\text { F1, F2, F3, V1, V2 } \\
\text { F1, F2, F3, Z1, Z2, Z3 } \\
\text { F1, A1, P1, P2, P3, V1, }\end{array}$ \\
\hline Hughes Aircraft (Aerospace) & $\begin{array}{l}\text { Culver City, Calif } \\
\text { Clifton, N.J }\end{array}$ & $\begin{array}{l}\mathrm{F} 1, \mathrm{~F} 2, \mathrm{~A} 3,(\mathrm{~A} 4), \mathrm{P} 3, \\
\mathrm{~V} 1, \mathrm{Z} 3,(\mathrm{Z} 4), \mathrm{N} 2, \text { (to } \\
40 \mathrm{Gc} / \mathrm{s} \text { ) } \\
\mathrm{F} 3, \mathrm{~V} 1\end{array}$ \\
\hline $\begin{array}{l}\text { Lincoln Lab. (M.I.T.) } \\
\text { Martin Co }\end{array}$ & $\begin{array}{l}\text { Lexington, Mass } \\
\text { Baltimore, Md.-. }\end{array}$ & $\begin{array}{l}\text { (F4, P4) (Note 1) } \\
\text { F1, F2, F3 (F4 to } 18 \\
\text { Gc/s), P1, V1, Z1, Z2, } \\
\text { Z3 (Z4 to } 40 \text { Gc/s) }\end{array}$ \\
\hline $\begin{array}{l}\text { McDonnell Aircraft Corp } \\
\text { Motorola AC Spark Plug Div }\end{array}$ & $\begin{array}{l}\text { St. Louis, Mo } \\
\text { Chicago, Ill }\end{array}$ & F1, F2, P1, P2, P3, V1, \\
\hline Motorola Comm. \& Elect. & Chicago, Ill.... & $\mathrm{F} 1{ }^{21}$ \\
\hline National Bureau of Standards_ & Boulder, Colo & $\begin{array}{l}\text { F1, F2, F3, (F4), A1, } \\
\text { A2, A3, P1, P2, P3, } \\
\text { (P4), V1, V2, E1, Z1, } \\
\text { Z2, Z3, Q1, Q2, N3 } \\
\text { (to 18 Gc/s) }\end{array}$ \\
\hline
\end{tabular}

\begin{tabular}{|c|c|c|}
\hline Lab & Location & ities \\
\hline NAA-Columbus Div. & Columbus, Ohio .. & $\mathrm{P} 2, \mathrm{~V}$ \\
\hline $\begin{array}{l}\text { Northeastern Engrg. Inc } \\
\text { Ohio State Univ-Antenna Lab } \\
\text { Philco WDL }\end{array}$ & $\begin{array}{l}\text { Manchester, N.H } \\
\text { Columbus, Ohio } \\
\text { Palo Alto, Calif }\end{array}$ & $\begin{array}{l}\text { Z1, Z2, Z3 } \\
\text { F1, F2, F3 } \\
\text { F1 (A4, P4) (Note 1) } \\
\text { F1, A1, A2, A3, P1, P2, } \\
\text { V1, Z2, N1, N2 }\end{array}$ \\
\hline $\begin{array}{l}\text { Pickard \& Bur } \\
\text { Polytechnic In } \\
\text { Premier Micro } \\
\text { RCA Laborato }\end{array}$ & $\begin{array}{l}\text { Walthe } \\
\text { Brookl } \\
\text { Portch } \\
\text { Moores }\end{array}$ & $\begin{array}{l}\mathrm{F} 1, \mathrm{~F} 2, \mathrm{~F} 3 \\
\text { A2, A3, P2, P3, Z2, Z3 } \\
\text { Z3 } \\
\text { (P4 to } 25 \mathrm{Gc} / \mathrm{s})(\mathrm{A} 4-\end{array}$ \\
\hline RA Standards La & Cambridge, Ohio_ & $2, \mathrm{Z1}$ \\
\hline andia ALO Standa & Albuquerque, N.Mex_ & $\mathrm{F} 1, \mathrm{~F} 2, \mathrm{~F} 3, \mathrm{~A} 1, \mathrm{~A} 2, \mathrm{P} 1$, \\
\hline pace Tech. Lab & Redondo Beach, Calif_ & $\mathrm{F} 1, \mathrm{~F} 2, \mathrm{~F} 3, \mathrm{P} 1, \mathrm{P} 2, \mathrm{P} 3$ \\
\hline Radio $\mathrm{Co}$ & $\begin{array}{l}\text { Woodland Hills, Calif } \\
\text { Hollywood, Calif } \\
\text { Great Neck, N.Y...- }\end{array}$ & $\begin{array}{l}\mathrm{F} 1, \mathrm{Z}, \mathrm{Z3} \\
\mathrm{A} 1, \mathrm{~A} 2, \mathrm{P} 1, \mathrm{P} 2, \mathrm{Z1}, \mathrm{Z} 2 \\
\mathrm{~F} 1, \mathrm{~F} 2, \mathrm{~F} 3, \mathrm{(F} 4, \mathrm{P} 1, \\
\mathrm{P} 2, \mathrm{P} 3,(\mathrm{P} 4), \mathrm{Z} 2, \mathrm{Z3}, \\
\text { (Z4), N2, N3, (N4) } \\
\text { (to } 40 \mathrm{Gc} / \mathrm{s} \text { ) }\end{array}$ \\
\hline$n c$ & $\begin{array}{l}\text { Newton, Ma } \\
\text { Dallas, Texa } \\
\text { Newark, Ohi }\end{array}$ & $\begin{array}{l}\mathrm{F} 3,(\mathrm{~F} 4) \text { (to } 36 \mathrm{Gc} / \mathrm{s}) \\
\mathrm{F} 3, \mathrm{~V} 2 \\
\mathrm{~F} 1, \mathrm{~F} 2, \mathrm{~A} 1, \mathrm{~A} 2, \mathrm{~A} 3, \mathrm{P} 1, \\
\mathrm{P} 2, \mathrm{P} 3,(\mathrm{P} 4), \mathrm{V} 1, \mathrm{~V} 2\end{array}$ \\
\hline $\begin{array}{l}\text { U.S. Army ERD Laboratory } \\
\text { U.S. Bureau Naval Weapons. }\end{array}$ & $\begin{array}{l}\text { Fort Monmouth, N.J } \\
\text { Pomona, Calif }\end{array}$ & $\begin{array}{l}\text { (to } 40 \mathrm{Gc} / \mathrm{s}) \\
\mathrm{F} 1, \mathrm{~F} 2, \mathrm{~F} 3, \text { (F4) (to } 30 \\
\text { Ge/s) } \\
\text { F1, F2, A1, A2, P1, P2 } 2 \\
\text { P3, V1, V2, Z1, Z2 }\end{array}$ \\
\hline $\begin{array}{l}\text { Univ. of California } \\
\text { Univ. of Ill. (Antenna Lab) } \\
\text { Univ. of So. Carolina }\end{array}$ & $\begin{array}{l}\text { Philadelphia, Pa } \\
\text { Los Angeles, Calif } \\
\text { Urbana, Ill } \\
\text { Columbia, S.C }\end{array}$ & $\begin{array}{l}\mathrm{F} 1, \mathrm{P} 1, \mathrm{P} 2, \mathrm{P} 3, \mathrm{~V} 1 \\
\mathrm{~F} 3,(\mathrm{~F} 4) \text { (to } 36 \mathrm{Gc} / \mathrm{s}) \\
\mathrm{Z} 3, \text { (Z4) (to } 60 \mathrm{Gc} / \mathrm{s}) \\
\text { (F4), (Z4) (30 to }\end{array}$ \\
\hline Varian Associat & Palo Alto, Calif & $\begin{array}{r}\mathrm{Gc} / \mathrm{s}) \\
\mathrm{F} 1, \mathrm{~F} 2, \mathrm{~F} 3, \mathrm{~N} 2, \mathrm{~N} 3\end{array}$ \\
\hline $\begin{array}{l}\text { Varian Assoc-Bomac Div } \\
\text { Weinschel Engineering }\end{array}$ & $\begin{array}{l}\text { Beverly, Mass } \\
\text { Gaithersburg, Md }\end{array}$ & $\begin{array}{l}\mathrm{F} 1 \\
\mathrm{~F} 1, \mathrm{~F} 2\end{array}$ \\
\hline Western Elect & Winston-Salem, N & $\mathrm{F} 1, \mathrm{~F} 2, \mathrm{~F} 3, \mathrm{~A} 1, \mathrm{~A} 3, \mathrm{~F}$ \\
\hline $\begin{array}{l}\text { Weston Instrument } \\
\text { Westrex Communic: }\end{array}$ & $\begin{array}{l}\text { Newark, N.J } \\
\text { New York, N.Y. }\end{array}$ & $\begin{array}{l}\mathrm{P} 1, \mathrm{P} 2, \mathrm{P} 3 \\
\mathrm{~F} 1\end{array}$ \\
\hline
\end{tabular}

Note 1 -Work, in 150 to $300 \mathrm{Gc} / \mathrm{s}$ range, is at lower accuracies than specified in code.

Capability codes

\begin{tabular}{|c|c|c|c|c|}
\hline Measurement field & $\begin{array}{l}10 \mathrm{Kc} / \mathrm{s}- \\
300 \mathrm{Mc} / \mathrm{s}\end{array}$ & $\begin{array}{c}300 \mathrm{Mc} / \mathrm{s}^{-} \\
3 \mathrm{Gc} / \mathrm{s}\end{array}$ & $\begin{array}{c}3 \mathrm{Gc} / \mathrm{s}- \\
12.4 \mathrm{Gc} / \mathrm{s}\end{array}$ & $\begin{array}{c}12.4 \mathrm{Gc} / \mathrm{s}^{-} \\
300 \mathrm{Gc} / \mathrm{s}\end{array}$ \\
\hline Frequency (to better than $1 \times 10^{-8}$ ) & F1 & $\mathrm{F} 2$ & F3 & $\mathrm{F} 4$ \\
\hline $\begin{array}{l}\text { Attenuation (to better than } 0.01 \\
\mathrm{db} / \mathrm{db}-40 \mathrm{db} \text { range). }\end{array}$ & A1 & $\mathrm{A} 2$ & $\mathrm{~A} 3$ & A4 \\
\hline $\begin{array}{l}\text { Power, CW unbalanced (to } 1 \% \text { or } \\
\text { better). }\end{array}$ & P1 & $\mathrm{P} 2$ & P3 & P4 \\
\hline $\begin{array}{l}\text { Voltage, CW unbalanced (to } 1 \% \text { or } \\
\text { better). }\end{array}$ & V1 & $\mathrm{V}_{2}$ & V3 & $\mathrm{V} 4$ \\
\hline Field strength, CW (to $5 \%$ or better) & E1 & E2 & E3 & $\mathrm{E} 4$ \\
\hline $\begin{array}{l}\text { Voltage standing wave ratio (to } 1 \% \text { or } \\
\text { better). }\end{array}$ & $\mathrm{Z} 1$ & $\mathrm{Z} 2$ & Z3 & $Z 4$ \\
\hline $\mathrm{Q}$ (to $1 \%$ or better) & Q1 & Q2 & Q3 & Q4 \\
\hline Noise, noise figure (at state-of-the-art). & N1 & $\mathrm{N} 2$ & N3 & $\mathrm{N} 4$ \\
\hline
\end{tabular}


The results of the survey, although indicative of the capabilities of the laboratories surveyed, is not to be regarded as complete or exclusive. It is expected that a continuing effort by Commission will provide supplementary data for later reports, and become more nearly a compendium of the total measurements standards capabilities within the United States.

\section{Part 2}

In the field of radiofrequency standards and measurement the United States, in common with several other countries of the world, looks to a central, legal entity for affirmation or confirmation of accuracy in measurements. The National Bureau of Standards, operating through the medium of its laboratories in Washington, D.C., and Boulder, Colo., occupies a preeminent position, and its measurement research activities are followed intently.

Metrologists in general and the Bureau in particular recognize the wealth of talent subsisting in the many measurements laboratories which support government services or are part of research and industrial operations. These activities, complete with their own facilities and personnel, contribute much knowledge to metrology and serve to crosspollinate fertile minds at the Bureau. As a consequence, the state-of-the-art of measurements accuracy advances as a natural outgrowth of Bureau research, or as a result of independent research elsewhere which in time is confirmed by the Bureau as a legalized standard or recognized technique.

A survey has been made of the measurement activities of a number of organizations which are performing measurement calibrations and research. These activities may be either loosely or closely associated, in a technical sense, with the Bureau and have gained recognition on a national scale for their individual capabilities. In addition, the Bureau itself supplies calibration services for the benefit of its own research activities, as well as for the country's activities at large, by operating the Radio Standards Laboratory at Boulder.

During the past three years, NBS has made available [Mockler, Beehler, and Snider, 1960; Atkinson, Beehler, Heim, and Snider, 1962], through the medium of its standard frequency broadcasts, an accuracy of $1.1 \times 10^{-11}$ as established by its cesium atomic standard-NBS-II. Derivation of this accuracy was aided to a considerable extent by employment of crystal oscillators controlled by highly stabilized, accurately cut quartz crystals [Sykes, Smith, and Spencer, 1962] supplied by the Bell Telephone Laboratories, formerly operating in North Andover, Mass., but transferred in 1962 to Allentown, Pa. [Sykes, Spencer, Smith, and Bell, 1962].

The Western Electric Co. at Winston-Salem, N.C., has developed ultrastable rf oscillators in the 2.5 and 5.0 Mes range with frequency drifts less than $4 \times 10^{-11}$ after one year operation. These units are presently employed in VLF broadcasts for the US
Navy and for use in the US Coast Guard Loran-C stations [Hunter and Starr, 1961].

Independent, corroborative work carried on by the U.S. Army Electronic R \& D Laboratory at Fort Monmouth during this period established the accuracy of cesium atomic standards when used as synchronized clocks [Redar, Winkler, and Bickart, 1961]. In addition, an evaluation program carried out by this Laboratory [Searles and Brown, 1962] measured the performance of rubidium vapor frequency standards developed by the Varian Associates Laboratory [Packard, 1962]. Varian's rubidium standard accuracy and stability, as determined by the USAER\&D Laboratory and by the NBS Boulder Laboratories, was demonstrated to differ less than $4.7 \times 10^{-11}$ parts from the U.S. Frequency Standard [Varian Assoc., 1962]. This standard, utilizing hyperfine transitions in optically pumped rubidium vapor, has now been made available commercially. Meanwhile, development of an atomic hydrogen frequency standard is in process [Vessot, 1962].

Development of a third cesium atomic frequency standard utilizing a $3-\mathrm{m}$ oscillating field separation is well on its way to completion at NBS. It is anticipated that use of a servosystem to control the frequency of the quartz oscillator will reduce the quartz spectral line width by 50 percent and increase the stability of the system. Initial experiments indicated a thallium beam standard was operable but had low efficiency.

The laboratory established by Pickard and Burns, Inc., at Waltham, Mass., at the present time is developing its own conception of the cesium frequency standard, under Air Force contract. During the survey period the company made available, through commercial channels, a phase-locked receiver to be employed in very-low-frequency phase comparison techniques employed in the precise control of frequency and timing.

Work on frequency standards utilizing maser principles has continued at several locations. At NBS, refinements to the ammonia beam maser consisting of the addition of a servo system to control the cavity tuning, resulted in determining the ability to reset the frequency to be about 3 parts in $10^{11}$. Meanwhile, at Fort Monmouth the USAERD Laboratory has continued its work on ammonia and hydrogen masers, supported in part by analyses conducted by the University of Colorado [Barnes, 1962] and specialists of the Martin-Marietta Corp. [19621963] in Baltimore, Md. In addition, laboratories at the following locations reported that they have conducted independent work on masers - International Telephone and Telegraph Co. in Clifton, N.J., Bell Telephone Laboratory at Murray Hill, N.J. Columbia University at New York, N.Y., Harvard University at Cambridge, Mass. [Ramsey and Kleppner, 1962], Massachusetts Institute of Technology at Cambridge, Mass., PRD Electronics, Inc., in Brooklyn, N.Y., and Varian-Bomac at Beverly, Mass.

During the past three years, the NBS Radio Standards Laboratory at Boulder has increased its 
measurement capabilities of rf voltage (coaxial-CW) to the values shown in table 1 .

Taвle 1. Voltage (CW, coaxial)

\begin{tabular}{|c|c|c|}
\hline Voltage range & Frequency range & $\begin{array}{l}\text { Measurement } \\
\text { accuracy }\end{array}$ \\
\hline $\begin{array}{l}1 \mu \mathrm{V} \text { to } 10 \mu \mathrm{V} \\
10 \mu \mathrm{V} \text { to } 100,000 \mu \mathrm{V} \\
10 \mu \mathrm{V} \text { to } 100,000 \mu \mathrm{V} \\
10 \mu \mathrm{V} \text { to } 100,000 \mu \mathrm{V} \\
0.1 \mathrm{~V} \text { to } 400 \mathrm{~V} \\
0.1 \mathrm{~V} \text { to } 400 \mathrm{~V} \\
0.1 \mathrm{~V} \text { to } 400 \mathrm{~V} \\
0.1 \mathrm{~V} \text { to } 20 \mathrm{~V}\end{array}$ & $\begin{array}{l}30 \mathrm{kc} / \mathrm{s} \text { to } 500 \mathrm{Mc} / \mathrm{s} \\
30 \mathrm{kc} / \mathrm{s} \text { to } 10 \mathrm{Mc} / \mathrm{s} \\
10 \mathrm{Mc} / \mathrm{s} \text { to } 400 \mathrm{Mc} / \mathrm{s} \\
400 \mathrm{Mc} / \mathrm{s} \text { to } 900 \mathrm{Mc} / \mathrm{s} \\
30 \mathrm{kc} / \mathrm{s} \text { to } 10 \mathrm{Mc} / \mathrm{s} \\
30 \mathrm{Mc} / \mathrm{s} \\
100 \mathrm{Mc} / \mathrm{s} \\
300 \mathrm{Mc} / \mathrm{s} \& 400 \mathrm{Mc} / \mathrm{s}\end{array}$ & $\begin{array}{l}\text { Percent } \\
5 \\
2 \\
3 \\
5 \\
0.1 \\
0.2 \\
1.0 \\
3.0\end{array}$ \\
\hline
\end{tabular}

A number of laboratories throughout the country have given evidence of their capability to measure voltages within the same regions, to an accuracy approaching that of NBS. Among those reporting are the radio frequency standards laboratories at Hughes Aircraft in Culver City, Calif.; Western Electric Co., in Winston-Salem, N.C.; Microwave Research Institute in Brooklyn, N.Y.; Bendix Corp. in Kansas City, Mo.; Hewlett-Packard Co. in Palo Alto, Calif.; Sperry Gyroscope Co. in Great Neck, N.Y.; Sandia Corp. in Alburquerque, N. Mex.; Stoddart Aircraft Radio Inc. in Hollywood, Calif.; Ballantine Laboratories in Boonton, N.J. [Uiga and White, 1960]; Douglas Aircraft Co. in Santa Monica, Calif.; Metrology Dept. BuWepsRep at Pomona, Calif.; Weinschel Engineering Co. at Gaithersburg, Md.; Boeing Co. Aero-Space Division at Seattle, Wash.; AVCO-R.A.D. at Wilmington, Mass.

Present capabilities for measuring rf power in unbalanced circuits at the NBS Radio Standards Laboratory [Hudson, 1960; Ecklund, Hudson, and Ondrejka, 1962] are listed in table 2. These capabilities include also the recent advances in the microwave region [Engel, 1961].

Other laboratories reporting a closely related ability include the following: Hewlett-Packard Co. of Palo Alto, Calif.; Bendix, Kansas City, Mo.; Sperry Gyroscope, Great Neck, N.Y.; Sandia, Albuquerque, N. Mex. [Mavis, Denney, and Still, 1962]; Stoddart Aircraft, Hollywood, Calif.; Metrology Dept. BuWepsRep, Pomona, Calif.; Weston Instruments, Newark, N.J. [Weston]; Hughes Aircraft, Culver City, Calif.; Microwave Research Institute, Brooklyn, N.Y.; Bell Telephone, Murray Hill, N.J.; Weinschel, Gaithersburg, Md. [Raff and Sorger, 1960; Weinschel and Hedrich, 1961]; Boeing, Seattle, Wash.; AVCO-R. A. D. at Wilmington, Mass; PRD Electronics, Brooklyn, N.Y. [Hopfer, 1962]; and FXR Inc., Woodside, N.Y. [Aslan, 1960].

A great deal of measurement research and development during these past 3 years has been centered in the determination of insertion loss or attenuation. Outstanding work has been productive of results advancing measurement accuracy by more than one order of magnitude. The results at NBS, tabulated in table 3, were derived from the research work of several specialists at the Boulder Laboratories [Cook and Allred, 1960; Engel and Beatty, 1960; Shafer and Bowman, 1962] supplemented by the collaborative work of Weinschel [1961] and Sorger.

\begin{tabular}{|c|c|c|}
\hline Power range & Frequency range & Accuracy \\
\hline \multicolumn{3}{|c|}{ 1. CW, coaxial } \\
\hline $\begin{array}{l}0.1 \mathrm{mw} \text { to } 5 \mathrm{w} \\
0.1 \mathrm{mw} \text { to } 5 \mathrm{w} \\
0.1 \mathrm{mw} \text { to } 5 \mathrm{w} \\
5.0 \mathrm{w} \text { to } 1 \mathrm{kw}\end{array}$ & $\begin{array}{c}30 \mathrm{kc} / \mathrm{s} \text { to } 30 \mathrm{Mc} / \mathrm{s} \\
30 \mathrm{Mc} / \mathrm{s} \text { to } 300 \mathrm{Mc} / \mathrm{s} \\
300 \mathrm{Mc} / \mathrm{s} \text { to } 1000 \mathrm{Mc} / \mathrm{s} \\
30 \mathrm{kc} / \mathrm{s} \text { to } 1000 \mathrm{Mc} / \mathrm{s}\end{array}$ & $\begin{array}{c}\text { Percent } \\
0.15 \\
0.25 \\
0.5 \\
1.0\end{array}$ \\
\hline \multicolumn{3}{|c|}{ 2. Pulsed, coaxial } \\
\hline $2 \mathrm{mw}$ to $2 \mathrm{kw}$ & 900 to $1200 \mathrm{Mc} / \mathrm{s}$ & 3.0 \\
\hline \multicolumn{3}{|c|}{ 3. CW, microwave } \\
\hline $1 \mathrm{mw}$ to $1 \mathrm{w}$ & 8.2 to $18 \mathrm{Gc} / \mathrm{s}$ & 0.5 \\
\hline
\end{tabular}

Table 3. Attenuation ( $C W$, coaxial)

\begin{tabular}{|c|c|c|}
\hline Attenuation range & Frequency range & Accuracy \\
\hline$d b$ & & $d b$ \\
\hline 0 to 60 & $30 \mathrm{Mc} / \mathrm{s}$ & $\pm\left(0.002+0.001 \frac{\mathrm{A}}{10}\right)$ \\
\hline 60 to 100 & $30 \mathrm{Mc} / \mathrm{s}$ & $\pm\left(0.003+0.001 \frac{\mathrm{A}}{10}\right)$ \\
\hline 0 to 60 & $100 \mathrm{Mc} / \mathrm{s}$ & $\pm\left(0.005+0.001 \frac{\mathrm{A}}{10}\right)$ \\
\hline 60 to 100 & $100 \mathrm{Mc} / \mathrm{s}$ & $\pm\left(0.01+0.001 \frac{\mathrm{A}}{10}\right)$ \\
\hline 0 to 70 & $1,10,60,300 \mathrm{Mc} / \mathrm{s}$ & $\pm\left(0.02+0.001 \frac{\mathrm{A}}{10}\right)$ \\
\hline $\begin{array}{l}0 \text { to } 60 \text { (fixed pads) } \\
0 \text { to } 60 \text { (variable atten) }\end{array}$ & $\begin{array}{l}300 \mathrm{Mc} / \mathrm{s} \text { to } 8 \mathrm{Gc} / \mathrm{s} \\
300 \mathrm{Mc} / \mathrm{s} \text { to } 8 \mathrm{Gc} / \mathrm{s}\end{array}$ & $\begin{array}{l} \pm 0.1 \mathrm{db} / 10 \\
\pm 0.05 \mathrm{db} / 10\end{array}$ \\
\hline
\end{tabular}

Within the United States, several laboratories report capabilities for measuring attenuation which are favorably comparable with NBS. In addition to Weinschel, Gaithersburg, Md., they are: Boeing, Seattle, Wash.; Bell Telephone, Murray Hill, N.J.; Microwave Institute, Brooklyn, N.Y.; Douglas Aircraft, Santa Monica, Calif.; Sandia, Albuquerque, N.M.; Bendix, Kansas City, Mo.; Stoddart Aircraft, Hollywood, Calif.; Metrology Dept. BuWepsRep, Pomona, Calif.; USÁF Health Annex, Newark, Ohio; National Aviation Facilities Experimental Center, Atlantic City, N.J.; US Ármy Lexington Signal Depot, Lexington, Ky.; Martin Co., Denver, Colo.; Frankford Àrsenal, Philadelphia, Pa.; and Sperry, Great Neck, N.Y. [James, 1962].

In the area of field-strength measurements, a great deal of work remains. With the advent of more stringent requirements upon government contractors to mitigate radiofrequency interference has come renewed demands upon NBS, and initiation of individual laboratory research. Measurements laboratories are forced to develop techniques both to establish signal and noise field strengths, and to determine optimum signal to noise relationships for reception of intelligence. Typical is the work of the Jet Propulsion Laboratory, Pasadena, Calif., in measuring system noise temperatures [Schuster, Stelzried, and Levy, 1961]. 
Conversely, laboratories also are engaged in the study of controlled propagation of noise as a research tool or as an environment to be applied in testing. Such laboratories as Hughes Aircraft in Culver City, Calif. [Mukaihata, Walsh, Bottjer, and Roberts, 1962; Rickey and Forward, 1962]; Empire Devices at Amsterdam, N.Y. [Knapp, 1960]; Polarad Electronics, Long Island City, N.Y.; Bomac Laboratories, Beverly, Mass.; Weinschel Engineering, Gaithersburg, Md. [Raff and Sorger, 1960]; Stanford University, Palo Alto, Calif. [Siegman, 1961] Ohio State University, Columbus, Ohio [Ko, 1961]; Sylvania Electric Products, Mountain View, Calif. [Tralle, 1962]; Varian Associates, Palo Alto, Calif. [Varian]; NBS, Boulder Laboratories [Estin, Trembath, Wells, and Daywitt, 1960; Wells, Daywitt, and Miller, 1962]; Airborne Instruments Laboratory, Mineola, N.Y. Massachusetts Institute of Technology, Cambridge, Mass., and Bell Telephone, Murray Hill, N.J., have reported direct application of their talents to specialized problems in these fields.

In an attempt to resolve some of the more pressing measurement problems which have arisen during the past 3 years, some consideration has been given to known but neglected principles. As a technique for the measurement of rf voltages, particularly magnitudes greater than $1000 \mathrm{v}$, study has been directed to employment of the Stark Effect as a relative measurement of voltage. Preliminary work is in progress at NBS, Boulder [Beers and Strine, 1962 and shows promise in its comparative simplicity by eliminating the necessity for voltage dividers. Direct comparison of rf to d-c voltages is conceivable. Possible resolutions in measurement of one part per million using field strengths of $10^{4} \mathrm{v} / \mathrm{cm}$ are forecast.

The accuracy of coaxial line measurements has always been handicapped by the errors introduced by the fittings. Several advances have been made toward the establishment of a universal compatible connector. Research work by Weinschel Engineering and General Radio Co. [Sanderson, 1961; Sanderson, 1962] on very accurate VSWR measurements has been coordinated with the connector development work of organizations such as General Radio Co., West Concord, Mass. [Zorzy, and Muehlberger, 1961] and NBS, Boulder [NBS, 1962]. In August 1962, a meeting of the AIEE Subcommittee on Standardization of Precision Coaxial Connectors was held at NBS Boulder. They attempted to resolve conflicts in mechanical dimensions and electrical impedances of the several commonly employed connectors. As a result of the meeting, the committee submitted to the parent AIEE Electronic and High Frequency Instrumentation Committee a Recommended Practice for Precision Coaxial Connectors.

The occurrence of radio telemetering transmission blackouts during the test reentry of missile elements into the atmosphere triggered measurement research into relationships between plasma generation and radio signal attenuation approximately 5 years ago. Since that time much original work has re- sulted in measurement techniques to establish cause and effect. Typical is the research at Ohio State University [Tischer, 1960] to accomplish the measurement of electromagnetic properties of a physically bounded plasma. This work has been enlarged at NBS [Northover, 1962; Johler, 1962; Marini, 1960 ; Branscomb, 1960] to measure reactions in a less restricted environment.

Application of optic principles to millimeter waves in the unbounded or nonwave guide state at the University of South Carolina [Litman, Fellers, and Mosely, 1961] established the use of prismatic devices as directional couplers or attenuators which are susceptible to theoretical calibration. These principles have been utilized in the development of a wave meter and a reflectometer through application of interferometric principles. Similarly, the conception of a plasma piston, magnetically accelerated toward an electromagnetic wave to generate millimeter waves by the mirrorlike reaction from the plasma, illustrates an imaginative application of the Doppler effect. Utilization of two-port networks by the University of Illinois Laboratory [Mittra and King, 1962] and the Microwave Research Institute of Polytechnic Institute of Brooklyn [Altschuler, 1962] has assisted in determining some propagation characteristics of plasmas.

The surge of activity encompassing normally propagated millimeter waves has resulted in development at Bell Telephone Laboratories, Murray Hill, N.J., of measurement devices to measure transmission gain or loss in waveguide and delay distortion [IRE, 1962].

An excellent example of mutual support of effort to disseminate knowledge of measurement techniques has been the work of the Metrology Depart of BuWepsRep in Pomona, Calif. during the past 3 years, in circulating specialized design notes to standards and calibration laboratories. These cover the fabrication and application of precision measurement instruments developed, for the most part, at the National Bureau of Standards. A number of laboratories not conversant with the work of the Bureau have, in this manner, been made aware of the value and application of micropotentiometers, thermal voltmeters, standard frequency comparators (high frequency), and phase tracking receivers.

\section{References}

Altschuler (1962), The measurement of arbitrary linear microwave two-ports, Proc. IEE (London) 109, Pt. B, Suppl., No. 23.

Aslan (Sept. 1960), Temperature-compensated microwatt power meter, IRE Trans. Instr. 9, No. 2.

Atkinson, Beehler, Heim, and Snider (Dec. 1962), A comparison of direct and servo methods for utilizing cesium beam resonators as frequency standards, IRE Trans. Instr. 11, No. 3.

Barnes (Dec. 1962), Millimeter wave transitions for frequency control, Univ. of Colorado, DA36-039, Sc-87277, and Sc85313, semi-final rept.

Barnes (Dec. 1962), Choice of a molecule for a beam frequency standard, IRE Trans. Instr. 11, No. 3.

Beers and Strine (Dec. 1962), Measurement of voltage by the use of the Stark Effect, IRE Trans. Instr. 11, No. 3. 
Branscomb (July 1960), Measurements and standards in plasma-physics and astrophysics, NBS Tech. Note No. 59.

Cook and Allired (Sept. 1960), A precision rf attenuator calibration system, IRE Trans. Instr. 9, No. 2.

Ecklund, Ḧudson, and Ondrejka (Dec. 1962), Measurement of $\mathrm{rf}$ peak pulse power by a sampling-comparison method, IRE Trans. Instr. 11, No. 3.

Engen (Apr.-June 1961), A bolometer mount efficiency measurement technique, NBS J. Res. 65C, No. 2.

Engen and Beatty (Apr.-June 1960), Microwave attenuation measurements with accuracies from 0.0001 to $0.06 \mathrm{db}$ over a range of 0.1 to $50 \mathrm{db}$, NBS J. Res. 64C, No. 2.

Estin, Trembath, Wells, and Daywitt (Sept. 1960), Absolute measurement of temperatures of microwave noise sources, IRE Trans. Instr. 9, No. 2.

Hopfer (1962), Properties of thermo-electric elements as microwave power detectors, 1962 IRE Internat. Conv. Record 10, Pt. 3.

Hudson (Sept. 1960), A precision rf power transfer standard, IRE Trans. Instr. 9, No. 2.

Hunter and Starr (Oct. 13, 1961), Precision timing and frequency control, Proc. 6th Annual Test Engineering Conf., Chicago, Ill.

IRE (1962), An accurate millimeter wave loss and delay measurement set, IRE Trans. Microwave Theory Tech. 10, No. 6

James (Dec. 1962), A high-accuracy microwave attenuation standard for use in primary standards calibration laboratories, IRE Trans. Instr. 11, No. 3.

Johler (Jan.-Feb. 1962), Reflection and transmission of radio waves at a continuously stratified plasma with arbitrary magnetic induction, NBS J. Res. 66D (Radio Prop.), No. 1.

Knapp (1960), An instrument for measurement of high rf power density, Lambdin Proc. Sixth Annual Conf. RFI Reduction, Armour Res. Foundation, Chicago, Ill., October $4,5,6,1960$.

Ko (June 1961), Temperature concepts in modern radio, Microwave J. 4, No. 6.

Litman, Fellers, and Mosely (1961), Non-waveguide transmission of millimeter waves, Univ. of So. Carolina, ASTIA Doc. AF-18(603)-43, August 7, 1961.

Marini (Sept.-Oct. 1960), Radiation and admittance of an insulated slotted-sphere antenna surrounded by a strongly ionized plasma sheath, J. Res. 64D (Radio Prop.), No. 5.

Martin-Marietta Corp. (1962-1963), Excitation and detection techniques for millimeter wave transitions, DA 36-039, Sc-87321, and Sc-90753, semi-final rept.

Mavis, Denney, and Still (Dec. 1962), Microwave pulse power measurements, IRE Trans. Instr. 11, No. 3.

Mittra and King (Jan. 1962), An impedance transformation method for finding the load impedance of a two-port network, IRE Trans. Microwave Theory Tech. 10, No. 1.

Mockler, Beehler, and Snider (Sept. 1960), Atomic beam frequency standards, IRE Trans. Instr. 9, No. 2.

Mukaihata, Walsh, Bottjer, and Roberts (Dec. 1962), Subtle differences in system noise measurements and calibration of noise standards, IRE Trans. Instr. 11, No. 3.

NBS (1962), A new precision coaxial connector, NBS Rept. No. 7277 .

Northover (Jan.-Feb. 1962), Reflection of electromagnetic waves from thin ionized gaseous layers, J. Res. NBS 66D, No. 1.
Packard (Dec. 1962), The optically pumped rubidium vapor frequency standard, IRE Trans. Instr. 11, No. 3.

Raff and Sorger (Sept. 1960), A subtle error in rf power measurements, IRE Trans. Instr. 9, No. 2.

Ramsey and Kleppner (Dec. 1962), The atomic hydrogen maser, IRE Trans., Instr. 11, No. 3.

Redar, Winkler, and Bickart (June 1961), Results of a longrange clock synchronization experiment, Proc. IRE 49, No. 6.

Rickey and Forward (Dec. 1960), Effects of external noise on radar performance, Microwave J. 3, No. 12.

Sanderson (Nov. 1961), A new high-precision method for the measurement of the VSWR of coaxial connectors, IRE Trans. Microwave Theory Tech. 9.

Sanderson (Jan. 1962), An accurate substitution method of measuring the VSWR of coaxial connectors, Microwave J. 5, No. 1.

Schuster, Stelzried, and Levy (Mav 1961), The determination of noise temperatures of large antennas, JPL Tech. Rept. No. 32-97.

Searles and Brown (May 1962), Evaluation of atomic frequency standards, USÄER and D Lab Tech. Rept. 2298.

Shafer and Bowman (1962), A modulated sub-carrier technique of measuring microwave attenuation, Proc. IEEE 109, Pt. B, Suppl. 23.

Siegman (Mar.-Apr., 1961), Thermal noise in microwave system, Microwave J. 4, No. 3-4.

Sykes, Smith, and Spencer (Dec. 1962), Performance of precision quartz crystal controlled frequency generators, IRE Trans. Instr. 11, No. 3.

Sykes, Smith, Spencer, and Bell (Dec. 1962), Performance of precision quartz crystal controlled frequency generators, IRE Trans. Instr. 11, No. 3.

Tischer (Sept. 1960), Measurement of the wave-propagation properties of plasma in the microwave region, IRE Trans. Instr. 9, No. 2.

Tralle (June 1962), Noise figure, Microwaves 1, No. 1.

Uiga and White (Sept. 1960), High frequency voltage calibration, IRE Trans. Instr. 9, No. 2.

Varian (Oct. 1962), Long-term performance data on Varian rubidium vapor frequency standards, Frequency Control Bull. No. 1, Varian Assoc.

Varian, Noise characteristics of klystrons, Varian Assoc. Application Engineering Bulletin No. 11.

Vessot (Dec. 1962), Design and performance of an atomic hydrogen frequency standard, IRE Trans. Instr. 11, No. 3.

Weinschel (Sept. 1961), An accurate attenuation measuring system with great dynamic range, Microwave J. 4.

Weinschel and Hedrich (June 1961), An rf voltage standard for receiver calibration, IRE Trans. Instr. 10, No. 1.

Weston, Engen microwave wattmeter system, Bulletin Z-49, Instruments Division, Newark 12, N.J.

Wells, Daywitt, and Miller (1962), Measurement of effective temperatures of microwave noise sources, 1962 IRE Internat. Conv. Rec. 10, Pt. 3.

Zorzy and Muehlberger (Nov. 1961), rf leakage characteristics of popular coaxial cables and connectors, Microwave J. 4, No. 11.

(Paper 68D5-360) 